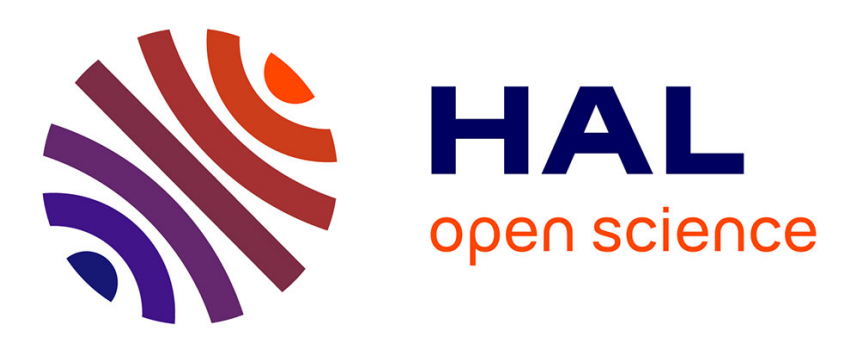

\title{
Does convection-permitting simulate better rainfall distribution and extreme over Guinean coast and surroundings?
}

Kouakou Kouadio, Sophie Bastin, Abdourahamane Konare, Vincent Ajayi

\section{- To cite this version:}

Kouakou Kouadio, Sophie Bastin, Abdourahamane Konare, Vincent Ajayi. Does convectionpermitting simulate better rainfall distribution and extreme over Guinean coast and surroundings? Climate Dynamics, 2020, 55, pp.153-174. 10.1007/s00382-018-4308-y . insu-01821831

\section{HAL Id: insu-01821831 https://hal-insu.archives-ouvertes.fr/insu-01821831}

Submitted on 4 Jan 2021

HAL is a multi-disciplinary open access archive for the deposit and dissemination of scientific research documents, whether they are published or not. The documents may come from teaching and research institutions in France or abroad, or from public or private research centers.
L'archive ouverte pluridisciplinaire HAL, est destinée au dépôt et à la diffusion de documents scientifiques de niveau recherche, publiés ou non, émanant des établissements d'enseignement et de recherche français ou étrangers, des laboratoires publics ou privés. 


\section{Climate Dynamics \\ Does convection-permitting simulate better rainfall distribution and extreme over Guinean coast and surroundings? \\ --Manuscript Draft--}

\begin{tabular}{|c|c|c|}
\hline Manuscript Number: & \multicolumn{2}{|l|}{ CLDY-D-17-00719R2 } \\
\hline Full Title: & \multicolumn{2}{|c|}{$\begin{array}{l}\text { Does convection-permitting simulate better rainfall distribution and extreme over } \\
\text { Guinean coast and surroundings? }\end{array}$} \\
\hline Article Type: & \multicolumn{2}{|c|}{ S.I. : Advances in Convection-Permitting Climate Modeling } \\
\hline Keywords: & \multicolumn{2}{|c|}{$\begin{array}{l}\text { high resolution, WRF, West Africa monsoon, Parameterization, Rainfall, convection } \\
\text { permitting }\end{array}$} \\
\hline Corresponding Author: & \multicolumn{2}{|l|}{$\begin{array}{l}\text { kouakou kouadio, Ph.D } \\
\text { Universite Felix Houphouet-Boigny } \\
\text { Abidjan, abidjan CÔTE D'IVOIRE }\end{array}$} \\
\hline \multicolumn{3}{|l|}{$\begin{array}{l}\text { Corresponding Author Secondary } \\
\text { Information: }\end{array}$} \\
\hline Corresponding Author's Institution: & \multicolumn{2}{|l|}{ Universite Felix Houphouet-Boigny } \\
\hline \multicolumn{3}{|l|}{$\begin{array}{l}\text { Corresponding Author's Secondary } \\
\text { Institution: }\end{array}$} \\
\hline First Author: & \multicolumn{2}{|l|}{ kouakou kouadio, Ph.D } \\
\hline \multicolumn{3}{|l|}{ First Author Secondary Information: } \\
\hline \multirow[t]{4}{*}{ Order of Authors: } & \multicolumn{2}{|l|}{ kouakou kouadio, Ph.D } \\
\hline & \multicolumn{2}{|l|}{ Sophie Bastin } \\
\hline & \multicolumn{2}{|l|}{ Abdourahamane Konare } \\
\hline & \multicolumn{2}{|l|}{ Vincent O. Ajayi } \\
\hline \multicolumn{3}{|c|}{ Order of Authors Secondary Information: } \\
\hline \multirow[t]{2}{*}{ Funding Information: } & $\begin{array}{l}\text { German Federal Ministry of Higher } \\
\text { Education and Research (BMBF), } \\
\text { WASCAL }\end{array}$ & Dr. kouakou kouadio \\
\hline & $\begin{array}{l}\text { France Government through the Service } \\
\text { de Cooperation et d'Action Culturelle } \\
\text { (SCAC) } \\
\text { (SCAC/2014/BE/002) }\end{array}$ & Dr. kouakou kouadio \\
\hline Abstract: & \multicolumn{2}{|c|}{$\begin{array}{l}\text { This research work focuses on the problem of climate simulation of rainfall over West } \\
\text { Africa and particularly over coastal countries of the Gulf of Guinea by Regional Climate } \\
\text { Models (RCMs). The sensitivities of Weather Research and Forecasting (WRF) Model } \\
\text { were tested for changes in horizontal resolution (convection permitting versus } \\
\text { parameterized) on the replication of West African monsoon for year 2014. Sensitivity } \\
\text { test was also performed for response of rainfall to changes in microphysics (MP) and } \\
\text { planetary boundary layer (PBL) schemes. Generally, the result shows that WRF are } \\
\text { able to replicates rainfall distribution with an adequate representation of the dynamical } \\
\text { features of West African monsoon system. The high-resolution (wrf-4km) shows dry } \\
\text { bias along the coast of the Gulf of Guinea but generally outperforms wrf-24km run } \\
\text { especially in replication of the extreme rainfall distribution. The dry bias along the } \\
\text { coastal area is suggested to not only related to convection but mostly to microphysics } \\
\text { and PBL parameterisation schemes. } \\
\text { Differences were noticed between the dynamics of WRF and ERA-interim outputs } \\
\text { despite the use of spectral nudging in the experiment which then suggest strong } \\
\text { interactions between scales. These differences were observed to be restricted mainly } \\
\text { to the low-layer monsoon flow in JJA. Both runs at } 24 \mathrm{~km} \text { and } 4 \mathrm{~km} \text { hardly simulate the } \\
\text { typical diurnal distribution of rainfall. The sensitivity of WRF to MP (only sophisticated } \\
\text { MP were tested) and PBL reveals a stronger impact of PBL than MP on rainfall } \\
\text { distribution and the most significant added value over the Guinean coast and }\end{array}$} \\
\hline
\end{tabular}


surroundings area was provided by the configurations using non-local PBL scheme (as ACM2). The changes in MP and PBL schemes in general seem to have less effect on the explicit runs (wrf- $4 \mathrm{~km}$ ) in the replication of the rainfall over the Gulf of Guinea and the surroundings seaboard. 


\section{Revision 2}

I would like to appreciate all the contribution from the reviewer to improve this work.

\section{COMMENTS FOR THE AUTHOR:}

Reviewer \#1: Second review of the paper:

Does convection-permitting climate simulation improve the replication of rainfall distribution and extreme over Guinean coast and surroundings? by Kouadio et al.

First, I would like to thank the authors that addressed part of my previous recommendations. The paper is improved. Nevertheless, after a careful second read, I have some main comments that require substantial modifications. I recommend major revision before accepting this study. Please see below my main recommendations.

Comments about the previous review:

1- About the answers of the previous revision. The authors reply only to my question without any modification of the text. These questions are not for my personal interest but reveal a lack in the explanations and should imply clarification in the text. The authors must have to reconsidere some of these previous points and clarify the main document. This is, for example, for the comments L31, L326 ...

\section{- L31: what "representations" means here? forecasted? please clarify}

This question has been addressed in the first line of the abstract.

Then, the first sentence has been modified from: "This research work focuses on the problem of representation of rainfall over West Africa and particularly over coastal countries of the Gulf of Guinea by Regional Climate Models (RCMs).” To:

This research work focuses on the problem of climate simulation of rainfall over West Africa and particularly over coastal countries of the Gulf of Guinea by Regional Climate Models (RCMs). 
- Paragraph starting L247 and Figure 3: The authors discuss the results over the sea, but I am more curious concerning the explanations of the intense dipole $\mathrm{E} / \mathrm{W}$ over the continent. This is maybe more important than over the Ocean because it affects directly the population.

The term Guinean Coast includes all the countries around the coast. It spread till $8 \mathrm{~N}$. Thus, the discussion is not only about across sea but concerns the surrounding countries. The question of dipole maybe addressed in multi-years works.

The text has been modified (L284 - 305).

"This figure 3 thus shows that indeed, the run at high resolution generally, outperforms the run at 24-km resolution over the Guinean band and southern Sahel, i.e. presents an upscaled addedvalue. There is however, some area where the high-resolution run seems to degrade the information instead of improving the simulation, especially over Ivorian coast, south-west of Guinea and Sierra Leone. One of the main reason would be related to the fact that the better skills of the explicit run are expected at daily and sub-daily scales and for extreme values while this AV is computed over 9 months. At seasonal scale, variability is mainly driven by large-scale dynamics that is not necessary improved by the higher resolution. On the other hand, Figure 2 has shown that in comparison to TRMM and CHIRPS datasets, WRF has good performance across near-Sahel and Sahel (north of $8^{\circ} \mathrm{N}$ ), but strongly underestimates precipitation across the coastal area of the surrounding countries of the Gulf of Guinea and mainly over the sea during the pre-onset period and at the end of the rainy season. This leads to strong dry bias from the sea to about $6 \mathrm{~N}$ (beyond the coast) during the rainy season over Sahel. One may suggest that the introduction of this dry bias along the Gulf of Guinea seaboard toward the equator (from $5^{\circ} \mathrm{N}$ and equatorward) into the model simulations (either parameterized and explicit convection), may be directly related to the forcing conditions. Moreover, previous works as Meynadier et al. (2010 and Marsham et al. (2013) revealed that the southward bias in the simulation of rainfall across West Africa, is an inherent problem for RCMs. Thus, model parameterisation schemes can be point out. Furthermore, convection-permitting simulation seems not to be able to correct effectively the dry bias. Therefore, convective parameterization alone may not be enough to 
explain this dry bias. Klein et al. (2015) found a similar dry bias in a cumulus, microphysics and boundary layer parameterization ensemble analysis of WRF version 3.5.1 and related it to the driving conditions."

- L268: gridded data means observed here? please clarify

The paragraph has been removed.

However, it was related to: "reliable and long-term daily observed gridded data"

- Paragraph starting L268 and Figure 4: The direct comparison between station datasets....

The section has been removed. The suggested plot can be seen in figure 5 .

- Paragraph starting L316 useless and questionable, I recommend to remove it The section has been removed as suggested

- L324: Please clarify the reason of this specific box

This clarification can be found in the text: L213-L318;

"This box is based (1) on the availability of ground-based observation which did not spread over the whole region and also (2) to allow for better comparison of previous works as Klein et al. (2015) and those that focused on onset like Sultan and Janicot (2000, 2003).”

- L326: 25th percentile of the rainy days (conditional) or of all the days?

The answer can be found in the text at line: L322-L324;

"It is worth noting that all the non-rain events have been beforehand removed in order to consider only the statistics based on effective rain events."

- L328: Could the authors explain how the regrid of the data can generate positive then negative changes of precipitation depending the hours of the day. It is not clear to me.

The section has been modified: L313-364

- Paragraph starting L332 is too descriptive.

The paragraph has been adapted: L313-364 
- $\quad$ Subsection 3.4 is also too descriptive. Please synthesize.

The section has been modified and figure changed: Subsection 3.3

- L383: The authors write "it provides more realistic estimations over the Sahel and emphasizes the benefit of the high-resolution simulation." But this is too speculative. The justifications are too few and based only on one figure that is not well adapted, and on one specific quantile.

The graph has been adapted to support the statement section 3.3

- L394: This is too specula

The graph has been adapted to support the statement. section 3.3

- Paragraph starting L397: I recommend to remove this paragraph. removed previously

\section{- $\quad$ L454 Ivory Coast}

Corrected: L500, L279, L280

2- About the scientific results and the impacts of the resolution. I am still convinced that most of the difference in term of precipitation values between WRF-24km and WRF-4km are explained by the size of each cells associated with each grid point (i.e. downscaling effect and not necessary a physical impact of the schemes). The authors should reconsider their methodologies to better prove these impacts. For example, what are the results of the new Fig. 5 if the authors would use the same resolution (by upscaling the WRF-4km simulation). Will they find results significantly different?

Figure 5 has been repeated with the regridded wrf-24km and wrf-4km into TRMM dataset grid scale. It is noticed from the analysis marginal differences between WRF native and regridded rainfall output at daily scale. The discussion can be found in the text at: L423-L432. The figure is added just after 
Similar analysis has been made at diurnal scale (L313:L364), and the result indicate that: upscaling WRF outputs into the grid scale of TRMM dataset has an effect on the number of the events regardless of the range of rainfall intensity, however, the timing is preserved.

Thus, results may suggest a combination of both grid scale factors and physics on the observed differences between the runs at $24 \mathrm{~km}$ (parameterized convection) and $4 \mathrm{~km}$ (convectionpermitting).

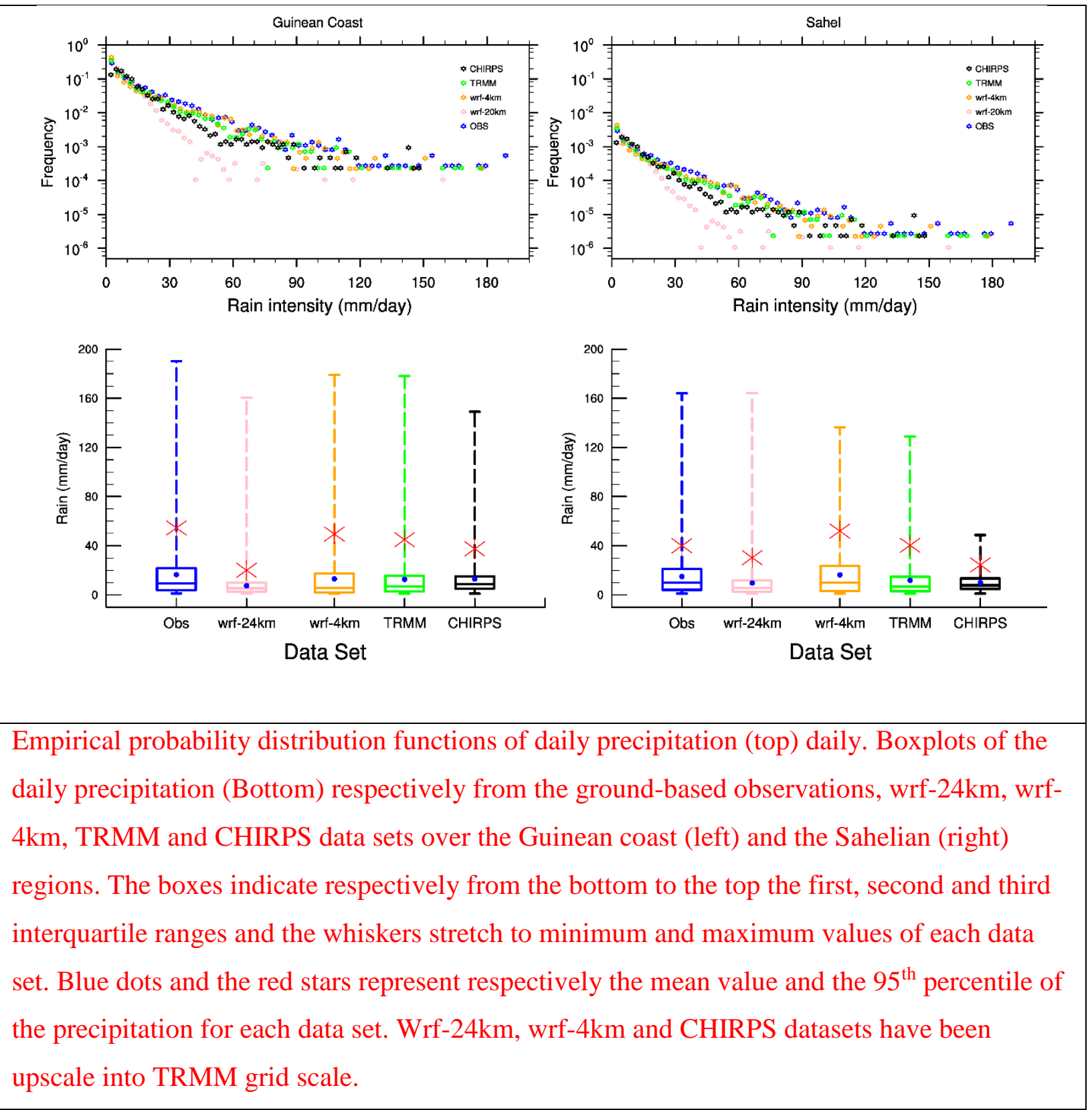


This comment seems more important in this second round since the difference between the two simulations in the new Fig. 6 and 7 are not very different. By the way, are these differences significant?

3- Despite some main comments of the previous review, some figures (see details below) have a too low quality relative to the standard of this journal. The authors have to improve most of them, and should be careful with the titles, axis, captions.

Main comments on the new document:

Abstract: To me the justification of this study, and more specifically why only PBL and MP schemes are the only schemes analysed, is not well exposed. Also, the authors are still using some speculative, or at least not justified, conclusions such as 'fairly replicates', 'good simulation'. These conclusions should be better assessed with significant test. As a reminder, this study uses only one year that reduces considerably the significance of the results, the authors should be as cautious as possible.

The limitation of the study related to the specific year has been mentioned at the end of the conclusion and the abstract has been revised.

\section{Section 3.1:}

Still too long and descriptive. For example, paragraph starting L284 must be simplified. L 293: 'Moreover, ERAI allocated shows its maximum precipitation toward the south' sounds weird to me

Paragraph L226-L239 of the previous version has been removed and the section has been modified to consider among other remarks the upscale of wrf-4km aspect. 
Paragraph starting L284 has been modified. L270-L297

\section{Section 3.2:}

There are some confusions when the authors discussed the quantiles of precipitation (Q95).

Sometimes they are using the value of Q95 in the observation, sometimes they are using this thresholds for each dataset. Please avoid mixing up the two methods.

The section has been modified and it also consider the upscale of wrf-4km.

Only L338-L340 mentioned Q95 using wrf-24km to discuss about the marginal occurrence of intense rain events with wrf- $24 \mathrm{~km}$.

L349. No ERAI is not used any more in this figure, please correct.

This has been corrected: L355

L363: The underestimation of the model (especially with the 24-km resolution) is quite logic. That should be mentioned.

Paragraph starting L363 and Figure 5. To me, the effect of the downscaling effect of the precipitation is the main driver of the results. The authors should compare the precipitation at the same resolution.

All the datasets have been upscaled to TRMM grid scale. The plot shows negligible changes and the result has been discussed on the text: L409:418. See figure added in this report.

Section 4.1 and figure 6 and 7. Could the authors check carefully what they plot and discus. In the title, caption and in the text, they mention the difference, but to me it is not. Please reconsider all this part.

The section has been modified L426-477. Differences can be observed between ERAI and WRF outputs especially at lower levels. For example, in the northern extend and intensity of monsoon flow, the intensity of African easterly Jet and the location and intensity of deep convection. 
Less important differences are observed between wrf- $24 \mathrm{~km}$ and wrf-4km and wrf-4km seems closer to ERAI.

At the end of the section 4.1, what are the conclusion of these difference. Do they authors consider the WRF-4 is better than WRF-24. This section is still too descriptive, general comments and main conclusions are missing.

The differences between wrf-24km and wrf-4km are not pronounced enough to fully consider that wrf- $4 \mathrm{~km}$ is better wrf-24km however, the explicit run shows result closer to the ERAI.

Paragraph starting 517: To me the results are mainly explained by the resolution of each product. Please use the same resolution to fairly compared these datasets.

Figure 8 has been rebuilt using the regridded wrf-24km and wrf-4km into TRMM dataset grid scale. As figure 5 there is marginal changes and we have same conclusion. 

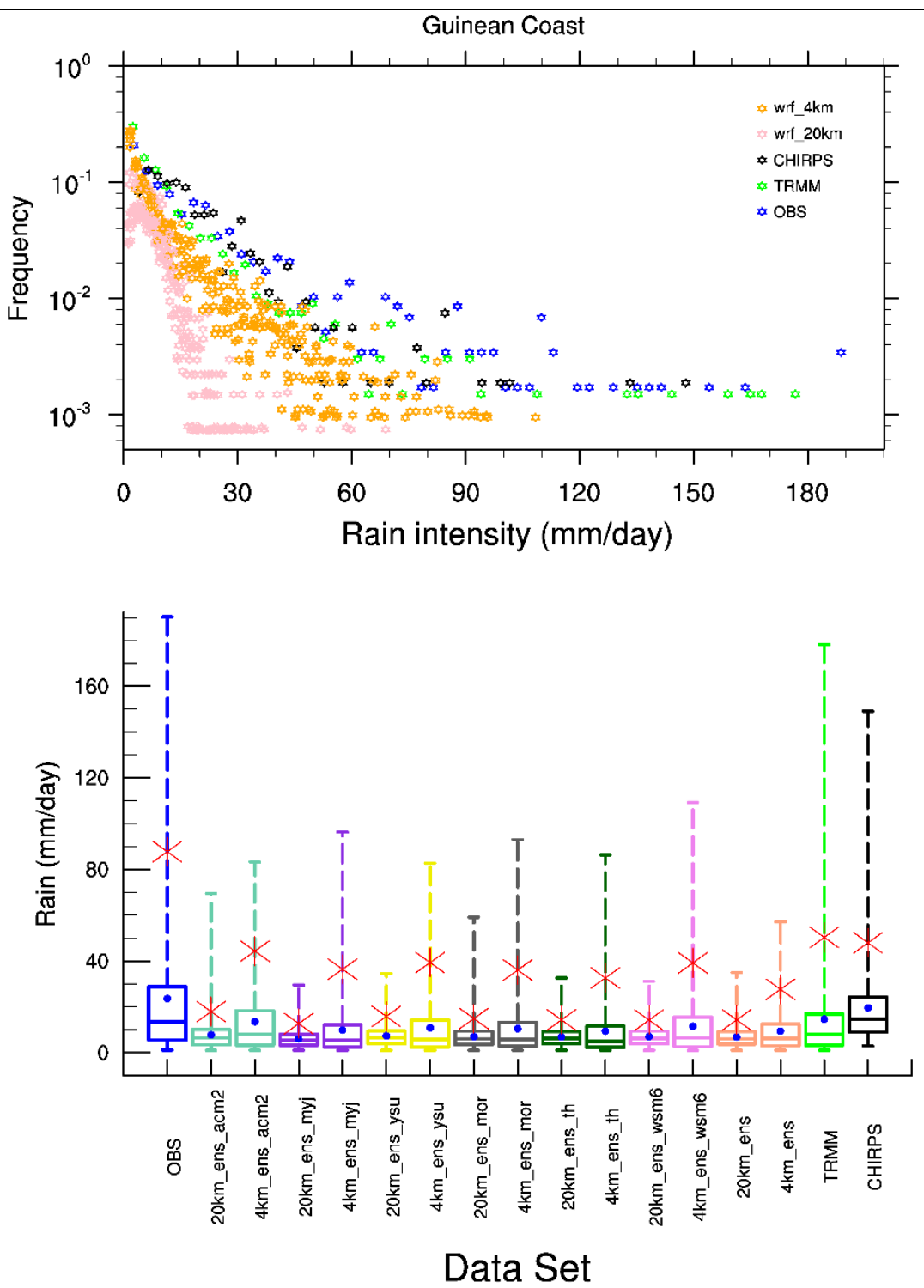

Empirical probability distribution functions of daily precipitation (top) daily. Boxplots of the daily precipitation (Bottom) over the Guinean coast (left) and the Sahelian (right) regions. Boxplots of the daily precipitation over the Guinean coast respectively from the ground-based observation, TRMM, ERA-interim and wrf-24km, wrf-4km from each ensemble group members of the different configurations. The boxes indicate respectively from the bottom to the top the first, second and third interquartile ranges and the whiskers stretch to minimum and maximum values of each data set. Blue dots and the red stars represent respectively the mean value and the 95 percentiles of the precipitation for each data set. Wrf-24km, wrf-4km and CHIRPS datasets have been upscale into TRMM grid scale. 
Figures:

Fig 4: The quality of these figures could be improved. No need of title for each panel (this should be indicated in the caption). Legend not readable and only one is required.

The figure has been modified

Figure 5, where are the numbers mentioned at the end of the caption

Corrected

Figure 6 and 7 Difference, are you sure?

Already answer in previous comments

Figure 7 Please keep the same structure as in Fig 6 (first column ERAI, second WRF-4, third WRF-24)

The figures 6 and 7 have modified accordingly (first column ERAI, second WRF-4, third WRF24)

Figure 9 and 10 not readable, low quality, need to be synthesized

The Figures 9 and 10 give detail information about the ensembles. It therefore going to be difficult to regroup them without missing the information. The quality of the graphs has been improved. 


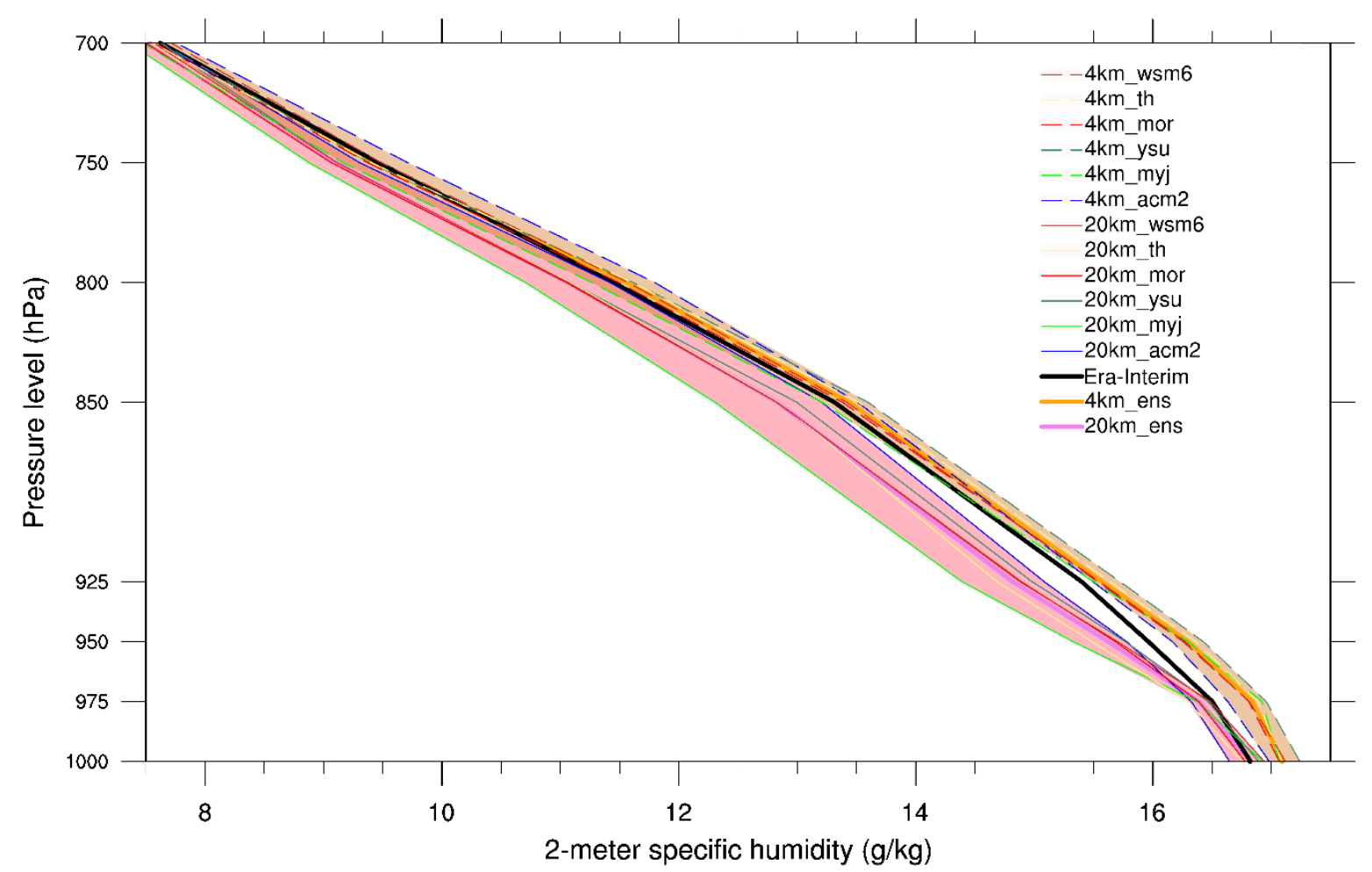

Fig. 9 Vertical profiles of specific humidity from wrf-20km and $4 \mathrm{~km}$ sub-ensembles group members and Era-interim data set. All the values are averaged from $10 \mathrm{~W}$ to $5 \mathrm{E}$. The pink and orange coloured areas mark the range of value respectively with wrf- $24 \mathrm{~km}$ and wrf4km. 

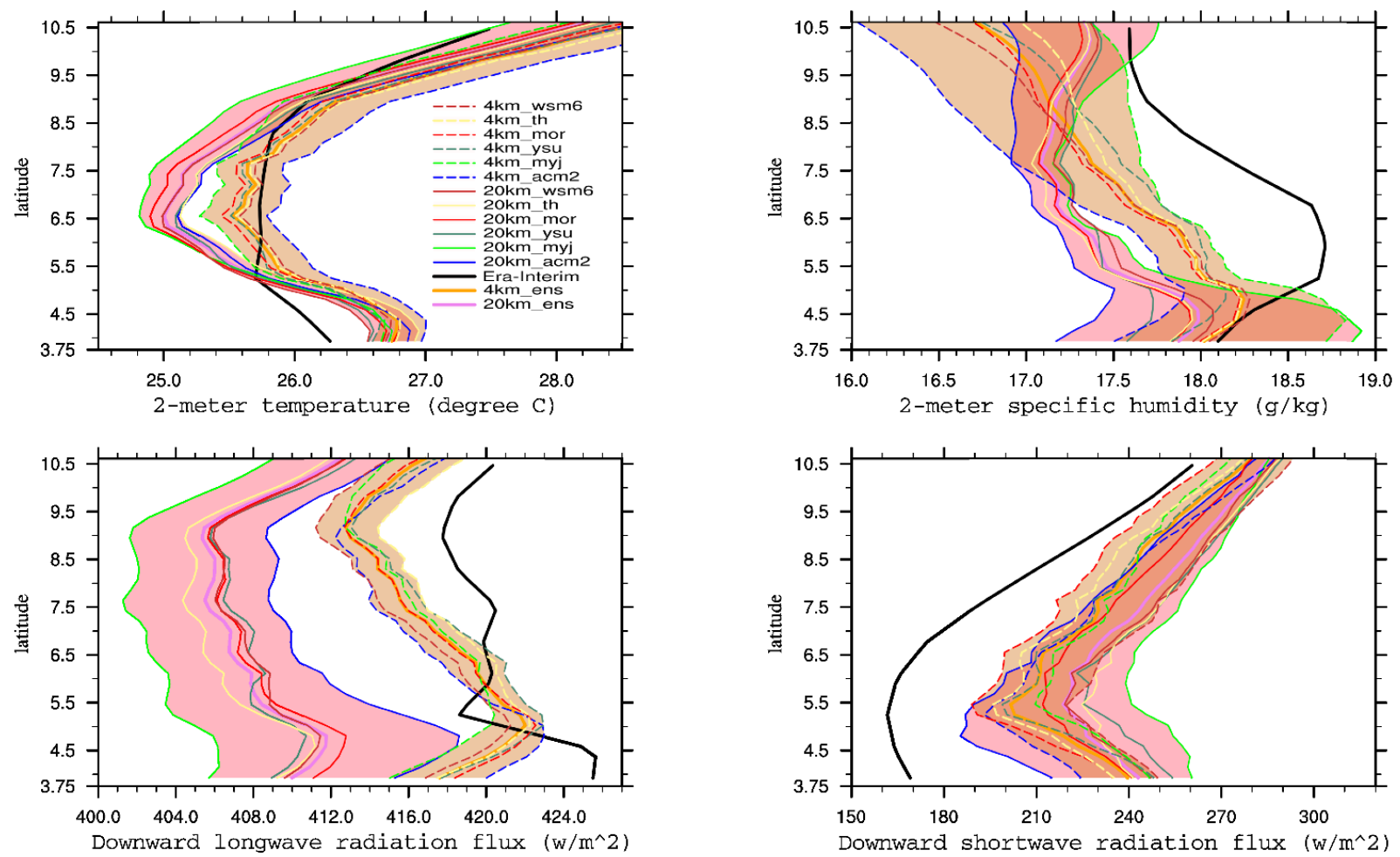

Fig. 10 Meridional evolution of 2-meter temperature, specific humidity, downward shortwave and longwave radiation fluxes from wrf- $20 \mathrm{~km}$ and $4 \mathrm{~km}$ ensemble group members and from Erainterim data set. All the values are averaged from $10 \mathrm{~W}$ to $5 \mathrm{E}$. The pink and orange coloured areas mark the range of value respectively with wrf-24km and wrf $4 \mathrm{~km}$.

Figure 12 is mentioned very briefly, consider to remove it.

The figure has been removed 


\section{Does convection-permitting simulate better rainfall distribution and extreme over Guinean coast} and surroundings?

KOUADIO $^{1 *}$, Kouakou., Sophie BASTIN ${ }^{2}$, Abdourahamane KONARE ${ }^{1}$., Vincent O. AJAYI ${ }^{3}$

1- Sciences des Structures de la Matière et de Technologie (SSMT), Université Felix HouphouëtBoigny, Abidjan, Côte d'Ivoire

2- LATMOS/IPSL, UVSQ Université Paris-Saclay, UPMC Univ. Paris 06, CNRS, Guyancourt, France

3- WASCAL Graduate Research Program on West African Climate System (WACS)/Federal University of Technology, Akure (FUTA), Nigeria

* Corresponding author's address :

Kouakou KOUADIO

Sciences des Structures de la Matière et de Technologie (SSMT), Université Felix Houphouët-Boigny, Abidjan, Côte d'Ivoire. / 01 BP 10578 Abidjan 01

E-mail : kk.kouadio@yahoo.fr/

\section{Acknowledgements}

We gratefully acknowledge the full scholarship and financial support from the German Federal Ministry of Higher Education and Research (BMBF) under the West African Science Service on Climate Change and Adapted Land Use (WASCAL) Doctoral Programme.

We acknowledge the computing resources for the simulations supported by the IPSL group for regional climate and environmental studies, with granted access to the HPC resources of GENCI/IDRIS (under allocation i2015016313) and IPSL mesocenter CLIMSERV.

Additional support was provided by France Government through the Service de Cooperation et d'Action Culturelle under reference SCAC/2014/BE/002.

We also acknowledge African Monsoon Multidisciplinary Analysis (AMMA) project for most of the ground-based data used in the study.

We thank Laboratoire Atmosphères, Milieux, Observations Spatiales, France (LATMOS) and all the entire staff for providing computing resources and other necessary supports.

I appreciate prof. A. KONARE of blessed memory for being an extraordinary mentor and for working under his directive during this research work. Thank him again for all the supports, opportunities and facilities he provided.

Finally, the authors are really grateful and thank the anonymous reviewers who contributed to improve this work. 


\section{Abstract}

34 This research work focuses on the problem of climate simulation of rainfall over West Africa and particularly over coastal countries of the Gulf of Guinea by Regional Climate Models (RCMs).

The sensitivities of Weather Research and Forecasting (WRF) Model were tested for changes in

37 horizontal resolution (convection permitting versus parameterized) on the replication of West African monsoon for year 2014. Sensitivity test was also performed for response of rainfall to changes in microphysics (MP) and planetary boundary layer (PBL) schemes. Generally, the result shows that WRF are able to replicates rainfall distribution with an adequate representation of the

41 dynamical features of West African monsoon system. The high-resolution (wrf-4km) shows dry

42 bias along the coast of the Gulf of Guinea but generally outperforms wrf- $24 \mathrm{~km}$ run especially in 43 replication of the extreme rainfall distribution. The dry bias along the coastal area is suggested to 44 not only related to convection but mostly to microphysics and PBL parameterisation schemes.

45 Differences were noticed between the dynamics of WRF and ERA-interim outputs despite the use 46 of spectral nudging in the experiment which then suggest strong interactions between scales. These 47 differences were observed to be restricted mainly to the low-layer monsoon flow in JJA. Both runs 48 at $24 \mathrm{~km}$ and $4 \mathrm{~km}$ hardly simulate the typical diurnal distribution of rainfall. The sensitivity of 49 WRF to MP (only sophisticated MP were tested) and PBL reveals a stronger impact of PBL than 50 MP on rainfall distribution and the most significant added value over the Guinean coast and 51 surroundings area was provided by the configurations using non-local PBL scheme (as ACM2).

52 The changes in MP and PBL schemes in general seem to have less effect on the explicit runs (wrf$534 \mathrm{~km}$ ) in the replication of the rainfall over the Gulf of Guinea and the surroundings seaboard.

55 Key words: high resolution, WRF, West Africa monsoon, Parameterization, Rainfall, convection 56 permitting 


\section{Introduction}

The West African region which extends from the Gulf of Guinea to the Sahel is an area which is subjected to alternating dry and wet seasons mainly linked to the monsoon, which influences the majority of annual precipitation. This region is an important source of aerosols and energy, which contributes to the formation of tropical cyclones. Therefore, this region greatly interacts with the Earth climate system and has been subject of numerous studies (Fontaine and Philippon 2000; Trenberth et al. 2000 ; Ali et al. 2005 ; Abiodun et al. 2008 ; Konare et al. 2008 ; Druyan et al. 2010 Moufouma-Okia and Rowell 2010 ; Sylla et al. 2010b ; Flaounas et al. 2012). West African region has also been identified as one of the poorest region in the world which depends mainly on rain-fed agriculture and one of the most vulnerable to climate change and climate variability (IPCC 2007). This vulnerability is aggravated by the interaction of 'multiple stresses' (drought frequency and duration, frequency of extreme events, among others), occurring at various levels, and the low adaptive capacity (IPCC 2007). Several studies (Omotosho et al. 2000; Sultan and Janicot 2000, 2003; Hagos and Cook 2007; Omotosho 2008; Pm. Ruti 2009; Janicot et al. 2010; Oettli et al. 2011) have argued that seasonal forecast of rainfall is crucial for socio-economic development in this sub-region. This is in the aim to (i) prevent extreme events like floods in the southern part, (ii) management of climate risk in agriculture (better preparedness for rain-fed agricultural activities), (iii) forestall outbreak of diseases in the Sahel region etc.

Although many studies have focused on the prediction of the rainfall, there exists challenges of reliable seasonal forecast due to several forcings. For example, the climate of this region is influenced by the interactions of various complex mechanisms (topography, oceanatmosphere interactions, atmosphere-biosphere exchanges etc.). In order to address these issues, several studies investigated the patterns of inherent variability in the West African monsoon at intra-seasonal, seasonal and interannual scales with the purpose to better understand the West African Monsoon (WAM) mechanisms (Adedoyin 1989; Nicholson 2001; Brooks 2004; Okumura and Xie 2004; 2004, Steiner et al. 2009 ; De Coëtlogon et al. 2010 ; Fink et al. 2010 ; Gbobaniyi et al. 2014 ; Meynadier et al. 2014) and precipitation characteristics (location, intensity, duration etc).

The relationship between rainfall and regional or large-scale dynamics over West Africa has been reported by earlier studies (Nicholson and Grist 2003; Sultan et al. 2003). The onset of 
87 the monsoon is associated with the intensification of the Tropical Easterly Jet (TEJ), a northward 88 shift and a weakening of the African Easterly Jet (AEJ), which is associated with a decrease of African Easterly Waves (AEWs) activity (Lavaysse et al. 2006; Sylla et al. 2010b). These results are in agreement with observation of Omotosho (2008) which found a stronger AEJ during dry years than during wet ones. Air-sea (through the Sea Surface Temperature (SST) in the Gulf of Guinea) interactions also play an active role in the amount of precipitation, its spatial distribution and northward migration (Leduc-Leballeur et al. 2013). (Vizy 2002) investigated the influence of the Gulf of Guinea's SST anomalies (SSTAs) on the climatology of the WAM and found an increase in rainfall over the Guinean coast area as a result of an increment in the lower tropospheric water vapour content due to increased evaporation over the warm SSTAs. This was accompanied by a decrease in rainfall over the southern Sahel. More generally, (Gaetani et al. 2017) have shown that the SST warming affects the Sahelian precipitation through modifications in the global tropical atmospheric dynamics, reducing the importance of the regional drivers. (Flaounas et al. 2012) and (Mohino et al. 2011) also linked the onset and the different phases of precipitation over West Africa to the convection over India and Indian ocean that generates Rossby waves which favors the heat low dynamics has been shown to strongly influence the onset of the monsoon and its intraseasonal variability (Lavaysse et al. 2009, 2010a, b), but also its variability at longer time scales due to radiative effects of water vapor that affect the regional dynamics (Evan et al. 2015). The increase of $\mathrm{CO}_{2}$ in the atmosphere also affects the precipitation at regional scale (Gaetani et al. 2017). An overview of the monsoon and its relationship with the climate system of the region is provided by Nicholson (2013).

All these efforts in addition to constant progress of models are expected to allow adequate representation of the WAM. However, at present day, models still have many difficulties to simulate the West African climate features. Several reasons are suggested to justify these underperformances ranging from the physics of the models, scale interactions, lacks of reliable and dense observation data suited to the resolution of the models. For example, Chang (2011) proposed that the limitation of climate models to reproduce the diurnal, seasonal and annual cycles of the rainfall over West Africa is related to a limited capacity of meteorological services in getting observations data set, and human and informatics resources. Indeed, the complex coupled systems that modulate climate system of the region are not well incorporated in current models, and one 
reason is that in most studies, precipitation is considered at monthly and regional scales, while precipitation over this area have a very strong variability when looking at higher temporal and spatial scales, with most of events occurring in the tails of classical precipitation distribution (either very intense events, either dry periods). Furthermore, Intergovernmental Panel on Climate Change (IPCC) acknowledged on its Third Assessment Report (TAR) that a model run at coarse resolution does not allow detailed extreme rainfall evaluation (Griggs and Noguer 2002). Then the simulation of the WAM at very high resolution is suggested to have a positive impact on the representation of the West African Climate, not only because the physical processes will likely be better represented but also because the explicit convection may help in the reproduction of this kind of distribution (Ban et al. 2014; Prein et al. 2015). However, some model improvements are likely necessary but the lack of observations to well define the distribution does not make the task easy.

Some earlier studies (Gallée et al. 2004; Doi et al. 2012; Holloway et al. 2012; Patricola et al. 2012; Marsham et al. 2013; Moufouma-Okia and Jones 2014; Small et al. 2014; Harlaß et al. 2017) showed an improvement of their simulations using high resolution simulation. Marsham et al. (2013) investigated the role of the moist convection over West Africa throughout a comparative study based on a horizontal resolution's cascade simulations using the UK Met Office Unified Model (UM). The runs are composed of grid spacing's of 4 and $12 \mathrm{~km}$ for 25 July to 4 August 2006. The first run is done with a convective parameterization and the second with an explicit convection. They found a better representation of the WAM with the explicit run. The major improvements come from a more realistic estimation of the latent and radiative heating in the northern part of West Africa and a better representation of the diurnal cycle of the rainfall. They noticed that these representations weaken the monsoon flow, the Sahel-Sahara pressure gradient, delaying the related diurnal cycle and modifying the interaction between monsoon and the boundary layer convection. They further reported that this result raises the importance of the interaction between monsoon and convection. In addition to the explicitly resolving of deep convection, convection-permitting run also allow a better representation of fine-scale orography and variations of surface fields. This is really important in mountainous regions and in areas with heterogeneous land surfaces like coastal and urban regions, wetlands, and patchy land covers. Therewith, resolving fine-scale surface heterogeneity is also of paramount importance due to the fact that it is an important forcing for deep convection (Prein et al. 2015). 
However, the high-resolution simulation of the WAM remains largely under explored because such type of high resolution modelling works requires high computational resources, innumerable computing time, and processors to high storage capacity. As a consequence, the studies conducted on the analysis of the WAM at high resolution are still too short (e.g. 11 days for Marsham et al. (2013)) to fully make a conclusion for a model in a climate mode, when the impact of the initial state will be cancelled. Therefore, the analysis of the WAM at very high resolution remains an important concern. In addition, the prevention of events with high social, economic and environmental impacts remains a constant challenge over the region. There is a need for identification of accurate models with optimal parameterizations for better understanding of the processes which allow a better prediction of West African rainfall variability and extreme and then provide the best way of using of regional dynamical model as a forecast tool and overcoming the difficulties of explaining the detailed rainfall and intense rainfall process over the West African region and particularly along the Guinean Coast and surrounding.

The study presented here evaluates the added-value of performing a convective permitting simulation in a climate mode, covering a longer period than a case study (several months) for the representation of rainfall distribution over Guinean coast, with a focus on heavy rainfall. Several combinations of parameterization schemes are compared in this explicit convective climate mode and the best combinations for replication of high rainfall events over Guinean Coast and surroundings are proposed. Section 2 describes the model and experiments which are compared and evaluated in section 3. Section 4 assesses the role of dynamics and physics in the performance of the different simulations. Finally, section 5 concludes the study.

\section{Model Description and Experiments}

Weather Research and Forecasting (WRF) Model is used in this study to first assess the capability of High-Resolution Regional simulation (convective-permitting) of West African Climate.

The first set of simulations uses two nested domains over the West African region (Fig.1) from March to September 2014. The coarser domain extends from $25^{\circ} \mathrm{W}$ to $30^{\circ} \mathrm{E}$ and from $10^{\circ} \mathrm{S}$ to $40^{\circ} \mathrm{N}$ with $24 \mathrm{~km}$ horizontal resolution. The inner domain is one-way nested from $17^{\circ} \mathrm{W}$ to $10^{\circ} \mathrm{E}$ 
177 and from $4^{\circ} \mathrm{N}$ to $20^{\circ} \mathrm{N}$ run at $4 \mathrm{~km}$ horizontal resolution (figure 1, black rectangle). Lateral 178 boundaries of the $24 \mathrm{~km}$ domain are forced with Centre for Medium-Range Weather Forecasts 179 (ECMWF) reanalyses ERA-interim (Dee et al. 2011) and it is spectrally nudged towards ERA180 interim for wavelength of $1680 \mathrm{~km}$ in the zonal direction and of $1576 \mathrm{~km}$ in the meridional one to 181 avoid unrealistic departures from the driving fields due to the size of the domain (Stauffer and 182 Seaman 1990; Salameh et al. 2010; Omrani et al. 2012). The nudging concerns zonal and 183 meridional wind and the temperature above the boundary layer. The configuration of WRF model 184 includes 51 vertical layers extending up to $50 \mathrm{hPa}$, and uses the Yonsei University (YSU) planetary 185 186 boundary layer scheme (Hong et al. 2006), the Noah land-surface model (Chen and Dudhia 2001), the Rapid Radiative Transfer Model for Global models (RRTMG) for shortwave (Dudhia 1989) and longwave (Mlawer et al. 1997) and the single-moment six-class (WSM6) grid-scale microphysics scheme (Hong and Lim 2006). Both domains share the same physics parameterizations except that in the nested domain, cumulus (CU) parameterization is not activated to allow explicit convection. The Kain-Fritsch (KF) convective scheme is used in the coarse domain with activation of interaction with RRTMG to take into account subgrid-scale radiative effects of clouds according to Alapaty et al. (2012), Herwehe et al. (2014).

The second set of runs is performed to focus on the physical processes of rainfall over the Guinean Coast, particularly on the influence of microphysics and boundary layer processes on the simulation of intense precipitations. These experiments consist of an ensemble of runs combining different boundary layer and microphysics schemes. Nudging is used in the coarse domain to ensure that the large-scale dynamics is the same in all the simulations of the ensemble. Table 1 provides a summary of the schemes used and the different experiments. For this second set of simulations, only one month is run (June 2014), over the domains shown by pink boxes in Fig.1. Resolutions of the two nested domains are $20 \mathrm{~km}$ and $4 \mathrm{~km}$ respectively. The nested domain focuses on the southern coastal area of West Africa.

An inter-comparison of the model outputs from these different configurations versus observation data is performed to find the best configuration that may provide an optimal representation of rainfall/heavy rain over West Africa in general and particularly over the Guinean Coast area. Observations come from satellites, ground-based stations and reanalyses. The groundbased data used here are daily records of temperature and precipitation over 74 stations across West Africa where the data are available for the year 2014 and selected according to the 
geographical position. The precipitation product from Tropical Rainfall Measuring Mission (TRMM) version 3B42V7 (3-hourly, daily) allows to cover the entire area with a $0.25^{\circ}$ spatial resolution (Huffman et al. 2007). In addition to TRMM data set, the Climate Hazards Group InfraRed Precipitation with Station data (CHIRPS) rainfall dataset is used. This dataset is spanning $50^{\circ} \mathrm{S}-50^{\circ} \mathrm{N}$ (and all longitudes), starting in 1981 to near-present, CHIRPS incorporates $0.05^{\circ}$ resolution satellite imagery with in-situ station data to create gridded rainfall (Funk et al. 2015).

Specific humidity and temperature at 2-m, shortwave and longwave downward radiation fluxes are also compared with ERA-Interim (at $0.75^{\circ} \mathrm{x} 0.75^{\circ}$ spatial resolution). Because of the limitation of the precipitation derived from ERAI as discussed by Di Giuseppe et al. (2013), the results with this dataset is not shown in the following graphs.

\section{Evaluation of the estimated rainfall}

\subsection{Seasonal analysis}

The simulation of rainfall by Regional Climate Model (RCM) over West Africa is still a full challenge as reported in many previous studies such as Marsham et al. (2013); Meynadier et al. (2014) ; Birch et al. (2014) and Panitz et al. (2014). Laprise et al. (2008) and Di Luca et al. (2012) stated that the initial concept of the nesting technique is to use RCMs like sophisticated "magnifying glasses" where "the generated small scales accurately represent those that would be present in the driven data if they were not limited by resolution". In this section of the work, the general improvement in the simulation of rainfall over West African region is assessed. Hereafter the terms wrf- $24 \mathrm{~km}$ and wrf- $4 \mathrm{~km}$ are used to identify respectively results from runs at $24 \mathrm{~km}$ and $4 \mathrm{~km}$ respectively.

The seasonal evolution of the rain belt is displayed on Figure 2 as a time-latitude diagram of 5-days run mean of precipitation averaged between $10^{\circ} \mathrm{W}-10^{\circ} \mathrm{E}$. The date of the onset is determined here by the transitional phase when precipitation decrease over the southern area around $5^{\circ} \mathrm{N}$ followed by its intensification northwards as indicated by Sultan and Janicot (2000, 2003) and followed by Flaounas et al. (2012). It can be more or less pronounced, depending on the year. 
236 The proposed oceanic phase by De Coëtlogon et al. (2010) and Leduc-Leballeur et al. (2011, 2013)

237 is shown in both TRMM and CHIRPS dataset. From April to end of May, maxima of precipitation

238 are generally located to the south $5^{\circ} \mathrm{N}$ and moved to around $5^{\circ} \mathrm{N}$ belt till it jumps northwards in

239 mid-July. This first phase of the monsoon latitudinal and seasonal displacement is not well

240 reproduced by both as WRF outputs estimate the maxima of rainfall over land even during spring.

241 This premature inland incursion of rainfall belt generates wet bias over land and dry bias over the

242 ocean and coastal region during spring and June. After the pre-onset period, both CHIRPS and

243 TRMM show a weakening of the rainfall in early July and it is followed by a fair recovery with a

244 maxima core around $7^{\circ} \mathrm{N}$ before moving northward. Thus, July $9^{\text {th }}$ can reasonably be chosen as

245 Sahelian onset date with TRMM and CHIRPS. In WRF, the monsoon rainfall belt moves

246 northwards but lower than CHIRPS and TRMM data. It is then difficult to define a day for the

247 onset with the model simulations. The farthest inland penetration is observed August $15^{\text {th }}$ and this

248 is replicated by both the observational datasets and WRF simulation. It is pertinent to note that the

249 observations (especially CHIRPS) show that during this period of maximum precipitation over

250 Sahel, there is a significant precipitation events along the Guinean Coast while WRF simulation

251 replicates a dry condition. After this date, the rainfall belts retreat gradually equatorward.

252

To assess the spatial value addition of the high resolution run as again the 'coarse

253 resolution run' and both WRF simulations as against ERA-interim (not shown), we computed the

254 added value (AV) based on the equation (1) proposed by Di Luca et al. (2013) and modified by

255 Dosio et al. (2014):

256

$A V=\frac{\left(X_{\bmod 1}-X_{O B S}\right)^{2}-\left(X_{\bmod 2}-X_{O B S}\right)^{2}}{\operatorname{Max}\left(\left(X_{\bmod 1}-X_{O B S}\right)^{2},\left(X_{\bmod 2}-X_{O B S}\right)^{2}\right)}(1)$ 
where $\mathrm{X}$ is the tested variable (here precipitation), the index mod1 is for the model with the coarser resolution, the index $\bmod 2$ for the simulation at higher resolution and OBS for Observations from TRMM and CHIRPS. The AV is computed over the 9 months and all data are regridded over the same grid (TRMM). Then the average value of AV for each grid point over the total period is plotted on Figure 3. AV is positive where model\#2's squared error is smaller than the model $\# 1$ 's one and negative otherwise. The positive values (cool colours) suggest an improvement of representation by the model $\# 2$ and the negative (warm colours) indicate where model $\# 2$ degrades the information provided by the model\#1. In this figure, the added value of wrf- $4 \mathrm{~km}$ to wrf- $24 \mathrm{~km}$ is computed using both TRMM (top)and CHIRPS (bottom) as reference dataset. The value addition of the wrf-4km as against wrf-24km which allows the evaluation of the usefulness of convective-permitting run, indicates an improvement of the simulation of average rainfall using the explicit run in comparison to wrf-24km in the half north of Ivory Coast, Ghana, Benin and part of Nigeria. On the contrary, the area westwards of Ivory Coast towards southwards of Senegal indicate that WRF-24km performs better. Above $14^{\circ} \mathrm{N}$, the signal is too weak to allow a conclusion. There is a very good agreement between the value added computed based on either on TRMM or CHIRPS dataset.

This figure 3 thus shows that indeed, the run at high resolution generally, outperforms the run at 24-km resolution over the Guinean band and southern Sahel, i.e. presents an upscaled addedvalue. There is however, some area where the high-resolution run seems to degrade the information instead of improving the simulation, especially over Ivorian coast, south-west of Guinea and Sierra Leone. One of the main reason would be related to the fact that the better skills of the explicit run are expected at daily and sub-daily scales and for extreme values while this AV is computed over 9 months. At seasonal scale, variability is mainly driven by large-scale dynamics that is not necessary improved by the higher resolution. On the other hand, Figure 2 has shown that in comparison to TRMM and CHIRPS datasets, WRF has shown result closed to the observation across near-Sahel and Sahel (north of $8^{\circ} \mathrm{N}$ ), but strongly underestimates precipitation across the coastal area of the surrounding countries of the Gulf of Guinea and mainly over the sea during the pre-onset period and at the end of the rainy season. This leads to strong dry bias from the sea to about $6 \mathrm{~N}$ (beyond the coast) during the rainy season over Sahel. One may suggest that the introduction of this dry bias along the Gulf of Guinea seaboard toward the equator (from $5^{\circ} \mathrm{N}$ and equatorward) into the model simulations (either parameterized and explicit convection), may be 
289

290

291

292

293

294

295

296

297

298

299

300

301

directly related to the forcing conditions. Moreover, previous works as Meynadier et al. (2010 and Marsham et al. (2013) revealed that the southward bias in the simulation of rainfall across West Africa, is an inherent problem for RCMs. Thus, model parameterisation schemes can be point out. Furthermore, convection-permitting simulation seems not to be able to correct effectively the dry bias. Therefore, convective parameterization alone may not be enough to explain this dry bias. Klein et al. (2015) found a similar dry bias in a cumulus, microphysics and boundary layer parameterization ensemble analysis of WRF version 3.5.1 and related it to the driving conditions. Here, if this dry bias could be related to a narrow north-south extent of the rain belt in WRF specially in WRF-24km as discussed in Klein et al. (2015) it may be mostly related to the microphysics and boundary layer parameterizations and not only to cumulus parameterization as already suggested in Flaounas, et al. (2011) and Klein et al. (2015). This result motivated the second set of runs, but this will be discussed later because we will first evaluate the impact of convective-permitting simulations at higher time scales.

\subsection{Rainfall diurnal cycle}

Figure 4 shows the diurnal cycle of rainfall occurrences over the Gulf of Guinea sub region for different categories of events based on their intensity. The 3-hourly average rainfall of each dataset is computed over the considered region $(4 \mathrm{~N}-8 \mathrm{~N} ; 10 \mathrm{~W}-10 \mathrm{E})$. This box is based (1) on the availability of ground-based observation which did not spread over the whole region and also (2) to allow better comparison with previous works as Klein et al. (2015) and those that focused on onset like Sultan and Janicot (2000, 2003). The obtained rainfall distributions have been divided into three subsets according to the TRMM distribution which is considered as the reference here: the light rain when the rain value is below or equal to the $25^{\text {th }}$ percentile of the TRMM distribution ( $3.46 \mathrm{~mm} / 3 \mathrm{hr})$, the medium rain with values between $25^{\text {th }}$ and $75^{\text {th }}(6.50 \mathrm{~mm} / 3 \mathrm{hr})$ percentiles, the intense rain events for values above or equal the $95^{\text {th }}$ percentile $(9.50 \mathrm{~mm} / 3 \mathrm{hr})$. It is worth noting that all the non-rain events have been beforehand removed in order to consider only the statistics based on effective rain events. Since the resolution of the dataset can impact the number of events, we computed these numbers using (1) the native grid of each dataset (solid line) and (2) the regridded datasets on the TRMM grid (dashed line). 
318 JJA over this sub-region is close to time UTC) than during the second half of the day, with a maximum of occurrence at 12 UTC according to TRMM observation dataset. Both WRF, in their native grids, replicate the shape of the diurnal cycle of light rain events with a sudden decrease at $12 \mathrm{UTC}$, but the occurrence of events is strongly overestimated in the parameterized run. If the explicit run capture well the timing of the maxima of the light rains, wrf-24km shows a 3-hours early peak of light rain events. On the other hand, wrf-4km either with its native grid or the regridded underestimates night lighter rain events. As of wrf- $24 \mathrm{~km}$, the regridded data shows more lighter rain events than its native data.

In the range of medium rain events, the diurnal cycle is of less variation in TRMM even though a maximum is observed at 15 UTC and a minimum between 03 and 12 UTC. WRF-4km, in its native grid spacing, shows a more pronounced peak of the maxima of medium rain events and a wide rain events under the observation while its regridded product almost continuous less rain events related to the native wrf- $4 \mathrm{~km}$. However, native and regridded grid from wrf- $4 \mathrm{~km}$ indicated the maxima of medium rain events at 15 UCT. Wrf-24km shows same pattern of diurnal cycles of the occurrence of the medium rain events either for the native and the regridded data. Nonetheless, a reduction in the number of rain events is noticed with the reggrided product. All datasets agree on the timing of occurrence of minimum medium rainfall events in between 03 and 12 UCT. Yet, wrf-24km displays the maximum events in the interval 15 and 18 UTC.

According to TRMM observation data set, intense rain events can occur anytime with nearly the same probability but none of the simulations reproduces this. The explicit run exhibits intense rain occurrence mainly from the evening to early morning with a maximum around 00 UTC. The same timing of the diurnal cycle is retrieved with the regridded wrf-4km with more intense rain events.

The relative absence of intense rain events with wrf- $24 \mathrm{~km}$ is related to the lower value of the $95^{\text {th }}$ percentile obtained by this convective parameterized run. The analysis of the occurrences 343 of intense rain based on the $95^{\text {th }}$ percentile of wrf- $24 \mathrm{~km}$ (figure not shown) demonstrates that this parameterized run mostly locates its maxima rain events in the afternoon (maximum at 15 UTC). This occurrence of maxima of intense rain events at 15 UTC with the parameterized run is mainly 346 due to the fact that convection is generally high when net radiative energy is at its maximum at 
about 15 UTC. The observed natural characteristics of rainfall are hardly replicated by models. This has been earlier highlighted in previous studies and suggested to be due to parameterisation of convection in the models (Marsham et al., 2013, Dirmeyer et al., 2012, Stephens et al., 2010). Wrf-4km seems to produce maximum of rain independently to the peak of the net radiative energy, except for medium rain-rates. In term of diurnal mean amount and timing of rain events, wrf- $4 \mathrm{~km}$ depicts results closest to the observations in comparison to wrf-24km.

Reggriding WRF outputs into the grid scale of TRMM dataset has an effect on the number of the events regardless of the range of rainfall intensity, however, the timing is preserved.

\subsection{Summary of the skill of the simulations on rainfall}

Figure 5 shows the daily Empirical Probability Distribution Functions and the boxplots of daily wrf- $24 \mathrm{~km}$ and wrf-4km precipitation compared to the ground-based observations, TRMM and CHIRPS data sets. Based on the available data and the regime of the rainy season, the area has been divided into two zones: the Guinean Coast $\left(4^{\circ} \mathrm{N}-8^{\circ} \mathrm{N}\right.$ and $\left.10^{\circ} \mathrm{W}-10^{\circ} \mathrm{E}\right)$ and the Sahelian region including the near Sahel $\left(10^{\circ} \mathrm{N}-18^{\circ} \mathrm{N}\right.$ and $\left.10^{\circ} \mathrm{W}-10^{\circ} \mathrm{E}\right)$. Only the available stations of each sub region are considered (CI1-7, BN1-3, GH2-5, GH7-8, GH12-62 for the Guinean Coast zone and GH1, GH6, GH9-11, BF1-7, NR1-7, GH40-44 for the Sahel region). For all datasets, the amount of precipitation at the nearest grid point of each station has been extracted. Following Lind et al. (2016), the PDF(fig.5, top) gives a detail on the spread/intensity of the daily rainfall for each of the dataset while the box plot (fig.5, bottom) for its part shows the summary of the distribution of rainfall (extremes, mean state). The percentiles on the box plots have been computed by considering only the wet days (the day where rainfall is above the threshold $1 \mathrm{~mm}$ ) over the period March-November. For each dataset, the number of events which overpass the $95^{\text {th }}$ percentile of ground-based observations is also indicated. The numbers on the figure provides a clear view of the ability of the model to statistically replicate intense rain events. They indicate the occurrence of intense rain events with the specifics dataset.

Over the Guinean Coast area, there is a relative underestimation of the overall rainfall tendency by both TRMM and CHIRPS estimation compared to the ground-based observations. They show value generally below the ground-based observation(top). The box plots (summary) show only $2.95 \%$ of rain events for TRMM and CHIRPS as intense and also 95\% of the rain 
intensities are below $39 \mathrm{~mm} /$ day for TRMM and $\sim 35 \mathrm{~mm}$ /day for CHIRPS). There are marginal differences between both satellite-based dataset as the exhibit very close frequency occurrence pattern of rainfall and similar summary in both Guinean Coast area and Sahel. Across both subdomain (Guinea Coast and Sahel), WRF-24km shows also less intense rain events as indicated with the PDF, the small boxes and the low value of its mean rainfall amount. In Guinea Coast, $95 \%$ of the rain events are less than $21.78 \mathrm{~mm} /$ day and only $0.18 \%$ of the rain events are intense, while the ground-based observation shows the $95^{\text {th }}$ percentile at $54.5 \mathrm{~mm} /$ day and a mean value of about $16.45 \mathrm{~mm} /$ day. The statistics displayed by the observations are well replicated by the wrf$4 \mathrm{~km}$, which shows $13.45 \mathrm{~mm} /$ day as mean value, and $4.66 \%$ of values are above the threshold of $54.4 \mathrm{~mm} /$ day. Thus, the explicit convection run, despite its dry bias at seasonal scale along the Guinean coastal area during the Sahelian phase of the monsoon, replicates more realistic precipitation extremes and qualitative distributions compared to the convective parametrized convection run.

Over the Sahelian region, the explicit run shows daily rainfall frequency distribution closer to TRMM, CHIRPS and the ground-based observation. The summary provides more intense rain events where $95 \%$ of the rain are up to $52.31 \mathrm{~mm} /$ day and the simulation runs at $24 \mathrm{~km}$ shows less intense rain events compared to the ground-based observation. $2.95 \%$ (wrf-24km) and $11.61 \%$ (wrf- $4 \mathrm{~km}$ ) of rain events are above the threshold of $40 \mathrm{~mm} /$ day corresponding to $95^{\text {th }}$ percentile of rainfall in the Sahelian region. The numbers of rain events based on wrf-4km are 4416 in the Gulf of Guinea; and 1499 in the Sahel. This matches better those of the observation with 3683 in the Gulf of Guinea; and 1119 in the Sahel than wrf-24km which shows 8250 in the Gulf of Guinea; and 2455 in the Sahel. Even though wrf-4km overestimates the number of intense rains and the intensity, it provides more realistic estimations precipitation extreme across both Guinea Coast and Sahel and emphasizes the benefit of the high-resolution simulation.

The low value of the occurrence of intense rain with wrf- $24 \mathrm{~km}$ compared to the highresolution run may be explained by the difference of the size of the grid scale. With a coarser grid scale, there is a higher probability that sub grid scale rainfall events might not be captured. (Chen and Knutson 2008). Previous studies (Emori et al. 2005; Iorio et al. 2004; Kharin et al. 2005) which assessed climate models by using ground-based stations data concludes that it is not a simple task to make a comparison between model output and station data set. They also reported that rainfall 
extreme indices might be influenced by the model resolution. The station records are essentially point estimates while the model output represents the rainfall variability over a wider spatial scales. Chen and Knutson (2008) also argued that Regional climate models are able to dynamically downscale extreme precipitation events to a spatial scale that is more comparable with observed rainfall analysis or station data. The grid scaling issues should be then reduced. Furthermore, even though it is not easy to cut off the physics from the pure resolution effect behind the differences between the runs at $24 \mathrm{~km}$ and $4 \mathrm{~km}$, it nevertheless emphasizes the usefulness of running the model at higher resolution at least to focus on the extreme events. On the other hand, both rainfall from wrf-24km and wrf- $4 \mathrm{~km}$ have been upscaled to TRMM dataset grid scale to assess the impact of the downscaling effect in the differences between those two (2) WRF outputs. Similar analysis as figure 5 has been made with the reggrided data and the results (figure not shown) indicated marginal changes between the native and reggrided rainfall. For example, the comparison of the value of the $95^{\text {th }}$ percentile with native and regridded shows is a reduction of about $7.41 \%$ (Gulf of Guinea) and 5.3\% (Sahel) for wrf-24km while wrf-4km indicates a decrease of 7\% (Gulf of Guinea) and 2.5\% (Sahel). This result may suggest a combination of both grid scale factors and physics on the observed differences between the runs at $24 \mathrm{~km}$ (parameterized convection) and $4 \mathrm{~km}$ (convection-permitting).

\section{Dynamical and physical role of the West African Monsoon}

4.1 Dynamics of the monsoon and moisture flux

The link between the dynamics of the WAM and its associated rainfall has been variously investigated and emphasized the role of the atmospheric circulation and specifically the Moisture Flux Convergence (MFC) (Cook, 1999; Druyan et al., 2010 ; Fontaine et al., 2008 ; Fontaine \& Philippon, 2000 ; Lebel et al., 2003 ; Nicholson, 2008, 2009, 2013 ; Nicholson et al., 2012 ; Sylla et al., 2010).

Figures 6 shows cross sections of the zonal wind from March-May (MAM), June-August (JJA) and September-November (SON) and averaged from $10^{\circ} \mathrm{W}$ to $10^{\circ} \mathrm{E}$. The first column represents the seasonal mean, while the second and third columns represent respectively the seasonal mean bias of wrf-4km and wrf-24km related to Era-Interim. Figure 7 shows seasonal 
434

435

436

437

438

439

440

441

442

443

444

445

446

447

448

449

450

451

452

453

454

455

456

457

458

mean of vertical profiles of the MFC, superimposed by the meridional-vertical wind vectors (v,w). For a better comparison, all data have been interpolated to the wrf- $24 \mathrm{~km}$ dataset.

The atmospheric circulations related to the WAM, characterized by the monsoon flow, the African Easterly Jet (AEJ) and the Tropical Easterly Jet (TEJ) are clearly replicated by the model outputs.

During spring (MAM), the core of the monsoon flow as shown by ERA-interim is $\sim 4 \mathrm{~m} . \mathrm{s}^{-1}$ while WRF is showing higher monsoon flow toward the coast (wrf- $24 \mathrm{~km}$ : up to $5 \mathrm{~m} / \mathrm{s}$ and wrf-4km up to $3 \mathrm{~m} / \mathrm{s}$ ) and lower flow in the north (up to $4 \mathrm{~m} / \mathrm{s}$ bellow for both wrf-24km and wrf-4km) (Fig. 6). Deep convection, associated with strong updrafts corresponding to the ascending branch of the Hadley cell, occurs between $6^{\circ} \mathrm{N}$ to $10^{\circ} \mathrm{N}$ and $800 \mathrm{hPa}$ to $200 \mathrm{hPa}$. This feature is well reproduced by the model outputs either wrf-24km or wrf-4km (Fig. 7).

During the summer (JJA), ERA-interim shows two distinguished cores of the monsoon flow. The major one is located around $15^{\circ} \mathrm{N}$ and the minor one at roughly $5^{\circ} \mathrm{N}$. Wrf- $4 \mathrm{~km}$ reproduces these two cores; however, the cores have the same intensity, the southern one is located further north than for ERA-interim, around $7.5^{\circ} \mathrm{N}$, while the second one is around $13^{\circ} \mathrm{N}$ (figure not shown). The AEJ is stronger in ERA-interim than in WRF simulations, while TEJ is weaker (Fig.6). Wrf-4km is showing difference up to $1 \mathrm{~m} / \mathrm{s}$ while wrf- $24 \mathrm{~km}$ reaches $2 \mathrm{~m} / \mathrm{s}$ in term of AEJ. Both WRF output show similar replication of TEJ (up to $2 \mathrm{~m} / \mathrm{s}$ lower). As expected, the area of deep convection has now moved to more northerly position from its position during the spring (MAM). Both model outputs replicate this feature with more inland penetration (up to $15 \mathrm{~N}$ ) than Era- Interim (below 13N and less pronounced (Fig. 7). This inland location of the deep convection is also coherent with the distribution of rainfall with WRF. A subsidence is observed around $5^{\circ} \mathrm{N}$ with wrf-24km and wrf-4km while in ERA-interim, it is located further beyond the equator (around $\left.2^{\circ} \mathrm{S}\right)$. All these differences are coherent with the more southward position of the maximum of rainfall in ERA-interim (Figs. 2 and 3) and explain the dry bias of ERA-interim over Sahel which 
is consistent with stronger AEJ and weaker TEJ ((Omotosho 2008)) and the dry bias of WRF above the sea. Indeed, the subsidence at $5^{\circ} \mathrm{N}$ generates a zone of strong divergence around the coastline $\left(1000-800 \mathrm{hPa}, 2^{\circ} \mathrm{N}-8^{\circ} \mathrm{N}\right)$ in the simulation, which is weaker and more to the south in ERAinterim. Note also that just above this layer, a layer of weak convergence around $700 \mathrm{hPa}$ is simulated with northerly wind and likely corresponds to the low-level shallow circulation (LLSC) induced by the Saharan heat low and discussed by (Zhang et al. 2006). This LLSC is not captured by the reanalysis.

During fall (SON), the configuration is similar to the spring one with less intensity. The southwesterly monsoon flow is confined southwards of $5^{\circ} \mathrm{N}$ with Era-Interim and stronger in WRF with more inland penetration. Wrf-24km shows more intense monsoon flow with a bias up to 4$5 \mathrm{~m} / \mathrm{s}$ and the explicit run shows bias below $3 \mathrm{~m} / \mathrm{s}$ relative to Era-Interim.

To conclude on the dynamics at seasonal and regional scales, several features can explain the differences in the seasonal precipitation patterns between ERA-interim and WRF simulations, despite the spectral nudging. This result reveals more or less important interactions between scales over this area and an impact of regional/local processes in the dynamics of this region. Therefore, the impact of physical processes seems not negligible in the representation of all elements of the WAM. The differences between the two WRF domains, which share the same physics but not convection, are mainly reduced to the low-level circulation, which has a stronger zonal component in WRF-24km than in WRF-4km. It affects the intensity of moisture convergence between 5 and $10^{\circ}$ N. Furthermore, wrf-4km shows less deviation from Era-Interim than wrf-24km in the replication of the main features of the WAM. However, these differences generally less pronounced or even marginal. Next section investigates the impact of physical processes by performing several simulations with different physics using the same large scale forcing.

\subsection{Impact of physical processes}

One of the major challenge of the current Convection-Permitting Models (CPMs) are the fact that they are still relying in older and traditional approach parametrization developed for 
boundary layer turbulent in mesoscale models. Furthermore, they are running at grid spacing that are not large enough to be in mesoscale model regime nor fine enough to be fallen into largescale eddy simulation regime as discussing in Tao and Moncrieff (2009)

\subsubsection{Sensitivity of WRF parametrizations on precipitation over the southern coastal area}

The aim in this section is to identify configurations that would be suitable for a better representation of intense rain events over the Guinean coast area. The past conducted works like Flaounas et al. (2011); Pohl et al. (2011); Klein et al. (2015), used parameterized convection. Prein et al. (2015) in a review CPMs underlined the limitation of our understanding about the microphysical processes and their interaction with resolved cumulus dynamics while Tao and Moncrieff (2009) indicated the grid spacing issue in the representation of boundary layer turbulent.

The current work focuses on the sensitivity of microphysics and PBLs to the resolved cumulus and contribute to the understanding of the microphysics processes and their interaction with resolved cumulus dynamics. Even though, the change of the convection scheme may modify the results, this will need too much resources and beyond the scope of this paper.

A second set of experiments has thus been performed but with smaller domains due to computing resources. The inner domain has been reduced to the Guinean coast area extending from the Ivory Coast to the Republic of Benin (Figure 1, pink rectangles). The period of the experiment is June 2014 when many flood events have been recorded along the littoral of the Gulf of Guinea and especially in Abidjan. The following different experiments use the configuration of the first set except for the microphysics (MP) and planetary boundary layer (PBL) schemes, which contribute to the vertical and horizontal distributions of moisture, which is a key issue in the Tropics for rainfall processes ((Neelin et al. 2009); (Holloway and Neelin 2009). Nine combinations of MP_PBL have been tested, using 3 different PBL schemes and 3 different MP schemes. These 9 combinations are thus associated with the Kain-Fritsch convective scheme in the coarser domain and with explicit convection in the inner domain. Since these parameterizations manage the atmospheric moisture distribution based on the same large-scale information provided by same lateral boundary conditions and the use of spectral nudging for wind and temperature, this protocol is well suited to understand the role of the physical processes in the simulated rainfall estimate over this specific area. 
The role of the PBL scheme is to determine the flux profiles of temperature and moisture within the whole atmospheric column, hence generating tendencies that serve as input for the CU and MP schemes at every model time step. Two types of PBL schemes exist according to the way they approach the turbulence equation closure problem: local closure schemes and non-local closure schemes. In the local closure schemes approach, the turbulence fluxes at each grid point are estimated based on prognostic turbulence kinetic energy (TKE). The Mellor-Yamada-Janjic (MYJ: (Janjic 1994; Janjić 2002) boundary-layer scheme used in the first part of this paper is of this type. The non-local closure schemes consider that scale eddies are of major importance to estimate vertical mixing in the boundary layer and in the free atmosphere. The PBL YonSei University (YSU: (Hong et al. 2006)) and the Asymmetric Convective Model version 2 (ACM2: (Pleim 2007) used in this section are based on this non-local closure. Moreover, the ACM2 is a combination of local and non-local turbulence closure techniques (Xie et al. 2012).

The microphysics scheme includes all processes that control the formation of cloud droplets and ice crystals, from their growth to their fallout as precipitation. It includes explicitlyresolved water vapour, cloud and precipitation processes. The MP scheme is in charge to remove excess atmospheric moisture in case the air is still saturated, which we will refer to us as nonconvective precipitation. The different MP schemes used are based on their classification of hydrometeors. The size distributions can differ from one scheme to another. The schemes considered in this work are the single-moment six-class (WSM6) scheme (Hong and Lim, 2006), the doublemoment Morrison (MOR) scheme (ten-class) (Morrison et al. 2009) and the New Thompson (TH) scheme (Thompson et al. 2008). Table 1 provides a summary of the schemes used and the different experiments.

Here attention is mostly given to the qualitative impact on rainfall over Guinean coast area. Figure 8 displays Empirical probability distribution functions of daily precipitation (top) which provides the frequency occurrence of the rain events according to the intensity and the daily boxplots of precipitation. These have been computed for wrf- $24 \mathrm{~km}$ and wrf- $4 \mathrm{~km}$ rainfall from each ensemble group members, TRMM and CHIRPS dataset across Guinea Coast area. The groups have been built using a fixed particular scheme following (Pohl et al. 2011). Thus, each ensemble group is the mean of all the configurations which use that particular scheme. The value of the rainfall is extracted at the nearest grid point of each station from the different run outputs, TRMM 
and CHIRPS. A single time series is computed for each data set. From these time series, we removed the days when observations are lacking and the dry days (where daily rainfall is below 1 $\mathrm{mm} /$ day). The result indicates significant underestimation of the overall rainfall intensity of wrf20km compared to TRMM, CHIRPS and ground-based observation as seen it with the low frequency occurrence of rain events against the intensity. Wrf-4km for its part is able to retrieve a good range of the rain events in regard to the intensity. CHIRPS dataset is showing statistics closer to the observed ground-based data compare to TRMM which miss more rain events. The boxplot of observations is then obtained from the total number of precipitating days of all stations of the Guinean area (CI1-7; BN1-3, GH2-5, GH7-8, GH12-62), i.e. 586 samplings (see Tab. 2). The same for TRMM and CHIRPS for which we obtained 656 and 553 samplings respectively. For the simulations, the numbers of the rain events are relatively high (see Tab. 2), with lower values at $4 \mathrm{~km}$ than at $20 \mathrm{~km}$ partly due to the effect of resolution, as already explained in the previous section.

In the month of June during which several flooding events were reported, $11.43 \%$ of events above the threshold of $54.5 \mathrm{~mm} /$ day were recorded. All the ensemble members show less intense rain events compare to the ground-based observation and TRMM data sets. In addition, the total rainfall amount was also underestimated by all the ensemble members (not shown). However, clearly, the main impact comes from the use of higher resolution since the mean, max, $3^{\text {rd }}$ interquartile and number of extreme events are always significantly higher in WRF-4km than in WRF-20km ensembles.

The occurrence of intense rain events is about $4.21 \%$ with the ensemble with the PBL scheme ACM2 which provides the closest statistics to TRMM data set, at 4km while with WRF$20 \mathrm{~km}$ run, all the ensembles do not reach at once the value of $54.5 \mathrm{~mm} /$ day or have an occurrence below $0.3 \%$. However, it is biased by the fact that the comparison with local rain gauges is better suited to a run at $4-\mathrm{km}$ resolution than at $20 \mathrm{~km}$ resolution. Nevertheless, it appears that physics also impacts the results. All statistics are in better agreement with observations than the others set of runs at a similar resolution (i.e. $1^{\text {st }}, 2^{\text {nd }}$ and $3^{\text {rd }}$ quartiles, mean, max and $95^{\text {th }}$ percentile). It is true for the domain at $20 \mathrm{~km}$ and the one at $4-\mathrm{km}$. Two other ensembles at $4 \mathrm{~km}$ outperform the others, not for all statistics but for the value of the $95^{\text {th }}$ percentile of precipitation and $3^{\text {rd }}$ quartile, 
575 which indicates a better ability to produce heavy rain: the ensemble using WSM6 as MP scheme 576 and the one using YSU as PBL scheme.

577 The same box plot was also performed over the Guinean Coast region (4N-8N; $10 \mathrm{~W}-5 \mathrm{E})$ for 578 WRF simulations and TRMM by using the same grid as TRMM before statistics are computed 579 (figure not shown). The result raised once again the better performance of the explicit convection 580 in the statistics of the rainfall distribution (moderate, intense and extreme rainfalls). This suggests 581 that the added value of the explicit run did not only come from the resolution but also from explicit 582 convection. It further emphasizes the usefulness of convection permitting in the analysis of 583 extreme rainfall and more general extreme events. However, convection permitting with high584 resolution run, is yet exhaustively enough to fully address the problem of simulating of rainfall 585 over West African region and especially over the Guinean Coast and surrounding.

\subsubsection{Impact of PBL scheme}

Both PBLs schemes ACM2 and YSU are non-local closure schemes which gives more attention to scale eddies on the estimation of vertical mixing in the boundary layer and the free atmosphere. The MYJ, which is a local closure, displays less intense rain events. The better performance of non-local closure schemes compared to the local one has been previously reported (Pleim 2007). The non-local closure has a better ability to replicate the turbulent vertical transport when both small-scale shear-driven turbulence and large-scale convective turbulence are taken into account (Holtslag and Boville 1993). This also takes into account large eddy transport and entrainment effects, which is essential for realistic representation of the convective boundary layer and the transport of humidity from the surface to the lower free troposphere, which is key for

597 triggering of convection (Holloway and Neelin 2009). The difference of vertical profiles of 598 humidity between the six PBL sub-ensembles is shown in Fig. 9 and clearly reveals that stronger differences appear between 925 and $750 \mathrm{hPa}$ than close to the surface, and the moister this layer,

600 the heavier the precipitation. These differences, however, are more noticeable with wrf- $20 \mathrm{~km}$ than 601 with wrf-4km. This may suggest a less influence of the PBL scheme on the convective permitting 602 run. 
The latitudinal evolutions of surface conditions are analysed via the latitudinal profile of 2-meter temperature (T2m), 2-meter specific humidity (Q2m), downward shortwave (SW) and longwave (LW) radiation fluxes (Fig. 11). The analysis reveals 2 distinctive groups over the Guinean Coast for T2m, Q2m, and LW, between the wrf-20km and wrf-4km. The explicit runs show higher surface temperature, more humidity and more incoming longwave radiation fluxes. It is also worth noting that there are important differences in the near surface humidity north of $8 \mathrm{~N}$. While wrf-4k runs show decrease in the humidity towards the north, wrf-20km runs show an increase. Important differences are also observed between the PBL ACM2 and MYJ for simulation of T2m and Q2m in wrf-24km or wrf-4km runs. ACM2 PBL is warmer and drier at the surface than MYJ, while the opposite is observed in the free troposphere (Fig. 10). An important difference is also observed for SW but only with wrf-20km. Over the ocean, and near the coast, the spread between the sub-ensembles is strong with both wrf-20km and wrf-4km. These differences over the ocean likely strongly impact the humidity advection inland. Wrf-20km shows more LW with ACM2 with less SW. This implies a deeper or more persistent cloud cover, despite the fact that it is drier and relatively warmer on the surface. At wrf-4km runs however, there are less differences between the value of SW and LW. Generally, wrf-20km simulates more SW arriving at the surface than wrf-4km and vice versa for the $\mathrm{LW}$.

\subsubsection{Impact of MP scheme}

The MP scheme is not a strong discriminant for the atmospheric specific humidity either with wrf$20 \mathrm{~km}$ and wrf-4km (Fig. 8). This is also true for T2m and Q2m (Fig 9). On the contrary, there are high differences between WSM6 and MOR in the representation of the SW with wrf-4km and slightly less with wrf-20km (Fig.10), and this may likely explain the differences in the rainfall distribution. The vertical profiles of occurrence (\%) of the Liquid Water Content (LWC) and the Ice Water Content (IWC, not shown) are displayed for different bin categories in Fig. 11 respectively. Figure 11 shows that LWC is sensitive to the resolution more than to the MP scheme used, since distributions are very similar between different MP ensembles, but very different between WRF-20km and WRF-4km. At 4km, there is higher occurrence of strong values of LWC between 925 and $750 \mathrm{hPa}$, consistent with higher specific humidity at this altitude. It impacts more strongly LW than SW, meaning that these clouds likely appear during nighttime. For IWC, differences between different MP schemes are stronger than between the two different resolutions 
633 (not shown). However, the main difference exists between $\mathrm{TH}$ and other schemes, while the 634 difference between MOR and WSM6 is weak. It thus cannot explain the difference of SW obtained 635 between MOR and WSM6. 


\section{Conclusions}

This work focuses on the sensitivity of the Weather Research and Forecasting (WRF) Model to horizontal resolution and physics schemes in the replication of West African precipitation for the year 2014. Several runs were performed with either parameterization or explicit convection. Both runs, wrf- $24 \mathrm{~km}$ and wrf- $4 \mathrm{~km}$, at seasonal scale, are able to replicate rainfall distribution over the region. The high-resolution which uses the explicit convection exhibits driest bias along the coast of the Gulf of Guinea but generally outperforms the $24 \mathrm{~km}$ run especially in the replication of the extreme rainfall distribution. The feature underlines the importance of high resolution on the analysis, characterization and further forecast of extreme events. At diurnal scale, based on TRMM data set, the major light rain events occur between mid-night and 12 UTC and the diurnal cycle of medium rain events has of less variation with a maximum observed at 15 UTC. Wrf-4km outperforms wrf-24km in the replication of these features especially the timing, and the number of events. Intense rain events can occur anytime with nearly the same probability but none of the simulations reproduces this. The parametrized convection run situated this maximum of occurrence of intense rain events in the afternoon at 15 UTC. This is mainly due to the fact that convection is generally high when net radiative energy is at its maximum, near 15 UTC for these regions. This has been earlier highlighted in previous studies and suggested to be intrinsic to parameterized convection (Marsham et al., 2013, Dirmeyer et al., 2012, Stephens et al., 2010). Furthermore, the explicit run exhibits intense rain mainly from the evening to early morning with a maximum around $00 \mathrm{UTC}$, independently to the peak of the net radiative energy. In short, the observed typical diurnal distribution of the rain is hardly well simulated by the model.

The analysis also reveals an adequate representation of the dynamical features of West African monsoon system with a less subsequent added value of permitting convection in the replication of low levels atmospheric circulation. However, irrespective to the spectral nudging for wrf-24km towards ERA-interim, there are differences of the dynamical structures between ERA-interim and wrf-24km. This reveals important interactions between scales over this area and not negligible impact of regional/local processes on the dynamics of this region. Therefore, the impact of physical processes seems crucial in the representation of all elements of the WAM. Both wrf- $24 \mathrm{~km}$ and wrf-4km well replicate the seasonal evolution of the AEJ. However, they show 
stronger monsoon flow and weaker AEJ compared to ERA-interim. The strong AEJ leads to inhibition of the vertical ascent of moisture in ERA-interim; thus, less development of clouds. The relative low value of the AEJ displayed with WRF allows the vertical ascent of the moisture leading to more frequent clouds. This is in agreement with the high value of precipitation observed with WRF simulations inland. On the contrary, there is a dry bias over the Gulf of Guinea and surroundings seaboard (from $8^{\circ} \mathrm{N}$ and equatorward) with either parameterized and explicit convections. This dry bias has been associated with a more northward location of the subsidence branch of the Hadley cell and a less south-north spread of the rain belt observed in WRF outputs. The differences between the two WRF runs, which share the same physics but not convection, are mainly reduced to the low-layer monsoon flow in JJA, which has a stronger zonal component in WRF-24km than in WRF-4km. It affects the intensity of moisture convergence between $5^{\circ} \mathrm{N}$ and $10^{\circ} \mathrm{N}$.

The impact of microphysics is not as strong as that of PBL schemes in either explicit or parametrized convection modes. However, some differences exist that can help in a better reproduction of heavy rainfall. Note that only complex MP schemes have been tested here, and it is possible that the use of more simple schemes may lead to different conclusions on the importance of MP scheme. The use of a non-local PBL scheme seems critical to better transport the low-layer humidity into the free troposphere and trigger convection.

The convection-permitting simulations thus seem well relevant to study extreme events (i.e. heavy precipitation). However, the simulations can be affected by the limitation of the domain size, the absence of two-way interactions between the inner domain and the rest of the globe, and the lateral boundary condition issues. Thus it is still ambiguous whether RCMs actually improve or degrade the larger scales information which is still a backbone for modeller and scientific community in general as underlined by Laprise et al. (2008).

The upscaling of wrf-4km to TRMM grid spacing (e.g. fig.4,6 and 7) suggested that differences may not be only related to grid spacing differences but a combination of both physical processes and grid scale effects. This study also indicates that the grid scale impact seems to be more pronounced at diurnal scale than daily and seasonal scales. In addition, as suggested by Prein et al. (2015) and Tao and Moncrieff (2009), the simulation at higher resolution bring out a key problem: the CPMs are still relying in the older and traditional 
696 approach parameterization developed for boundary layer turbulence in mesoscale models. In the 697 other hand, the current grid spacing of CPMS are not fine enough be into eddy simulation regime nor coarser to be consider as mesoscale models. This problem of upscaling is of paramount importance and need to be addressed however, this is beyond the scope of the current work.

The current study focuses only on a specific year due to the coast of such experiment. It is then important to extend to several years to allow better assessment of physical processes and statistical analyses. Such work needs subsequent cluster resources and is beyond the scope of this paper. The use of only three (3) microphysics and PBL and one convective parameterization scheme may be a limitation of the methodology.

This work is a first step in performing a set of comparison of different configuration that use various microphysics, PBL schemes and permitting convection. The current study justifies a need for large project work which will focus on the interaction between convection resolving and microphysics and PBLs schemes etc. It will contribute to better assess the skill of WRF in the replication of regional and more local physical processes. Furthermore, in order to fully isolate the changes related to the permitting convection from the pure grid scale impact (resolution) one may need a set of experiments using explicit and parameterized convections both carried at the same resolution. These are in the perspective of the Ivorian new computer center which will allow such expensive experiments. 


\section{$716 \quad$ List of Tables}

717 Table 1: Cumulus, microphysics and planetary boundary layer schemes used for the experiments 718

\begin{tabular}{|c|c|c|}
\hline & PHYSICAL OPTION & REFERENCES \\
\hline CUMULUS & Kain-Fritsch (KF) & (Alapaty et al. 2012) \\
\hline \multirow{4}{*}{ MICROPHYSICS } & Morrison double-moment (MOR) & (Morrison et al. 2009) \\
\hline & New Thompson (TH) & (Thompson et al. 2008) \\
\hline & WRF Single-Moment 6-class (WSM6) & Hong and Lim 2006 \\
\hline & Asymmetric Convective Model V2 (ACM2) & (Pleim 2007) \\
\hline \multirow{2}{*}{$\begin{array}{l}\text { PLANETARY } \\
\text { BOUNDARY } \\
\text { LAYER }\end{array}$} & Mellor-Yamada-Janjic (MYJ) & (Janjic 1994) \\
\hline & Yonsei University (YSU) & (Hong et al. 2006) \\
\hline
\end{tabular}

721 Table 2: Total number of rainy events over 1410 possible.

\begin{tabular}{|l|l|}
\hline Data set & number of rain events \\
\hline Observation & 586 \\
\hline WRF_ens_acm2_20km & 1312 \\
\hline WRF_ens_acm2_4km & 665 \\
\hline WRF_ens_myj_20km & 1238 \\
\hline WRF_ens_myj_4km & 1001 \\
\hline
\end{tabular}




\begin{tabular}{|l|l|}
\hline WRF_ens_ysu_20km & 1323 \\
\hline WRF_ens_ysu_4km & 992 \\
\hline WRF_ens_mor_20km & 1255 \\
\hline WRF_ens_mor_4km & 938 \\
\hline WRF_ens_th_20km & 1340 \\
\hline WRF_ens_th_4km & 878 \\
\hline WRF_ens_wsm6_20km & 1321 \\
\hline WRF_ens_wsm6_4km & 1025 \\
\hline WRF_ens_20km & 1353 \\
\hline WRF_ens_4km & 1070 \\
\hline TRMM & 656 \\
\hline CHIRPS & 553 \\
\hline
\end{tabular}

722

723

724

725

726

727 


\section{List of figures}
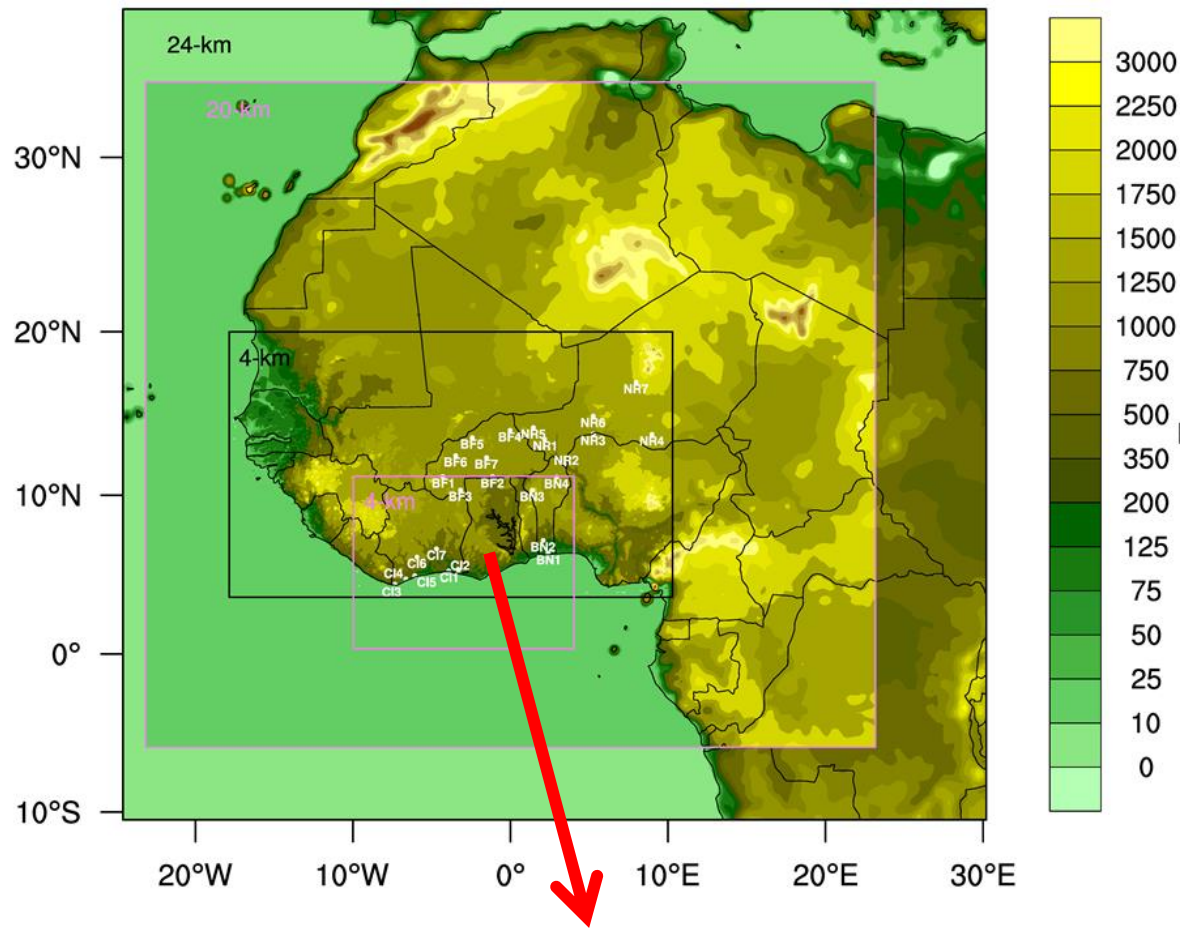

2250

2000

1750

1500

1250

1000

750

${ }^{500} \mathrm{~m}$

350

200

125

75

50

25

10

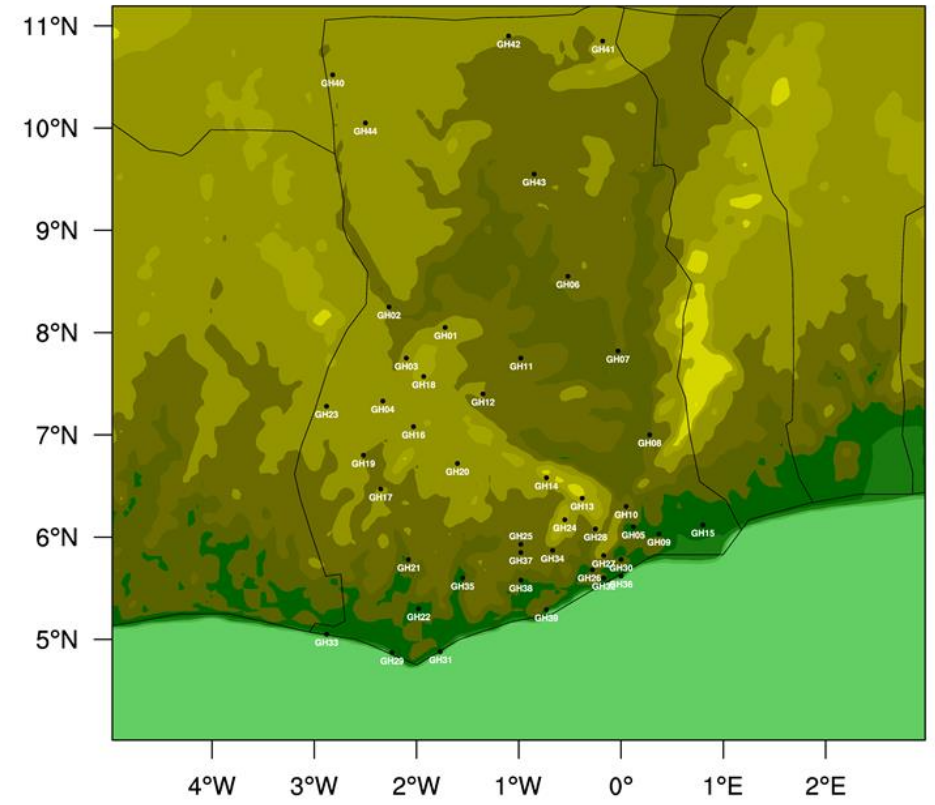

Fig. 1 Top: WRF model domain and elevation (m); parent domain at $24 \mathrm{~km}$ horizontal resolution $\left(25^{\circ} \mathrm{W}-30^{\circ} \mathrm{E}, 10^{\circ} \mathrm{S}-40^{\circ} \mathrm{N}\right)$. The nested domain is depicted by the back box $\left(17^{\circ} \mathrm{W}-10^{\circ} \mathrm{E}, 4^{\circ} \mathrm{N}-20^{\circ} \mathrm{N}\right)$ black boxes (first set of runs). The pink boxes correspond to the domains for the second set of runs (sensitivity to MP and PBL schemes) where parent domain is at $20 \mathrm{~km}$ horizontal resolution $\left(25^{\circ} \mathrm{W}-\right.$ $\left.30^{\circ} \mathrm{E}, 10^{\circ} \mathrm{S}-40^{\circ} \mathrm{N}\right)$. The nested domain covers the southern coastal area $\left(10^{\circ} \mathrm{W}-5^{\circ} \mathrm{E}, 0^{\circ} \mathrm{N}-12^{\circ} \mathrm{N}\right)$. The white dots indicate the ground-based stations used. Bottom: Zoom over Ghana (Table 1 provides the name and coordinates of the stations cited in the manuscript) 

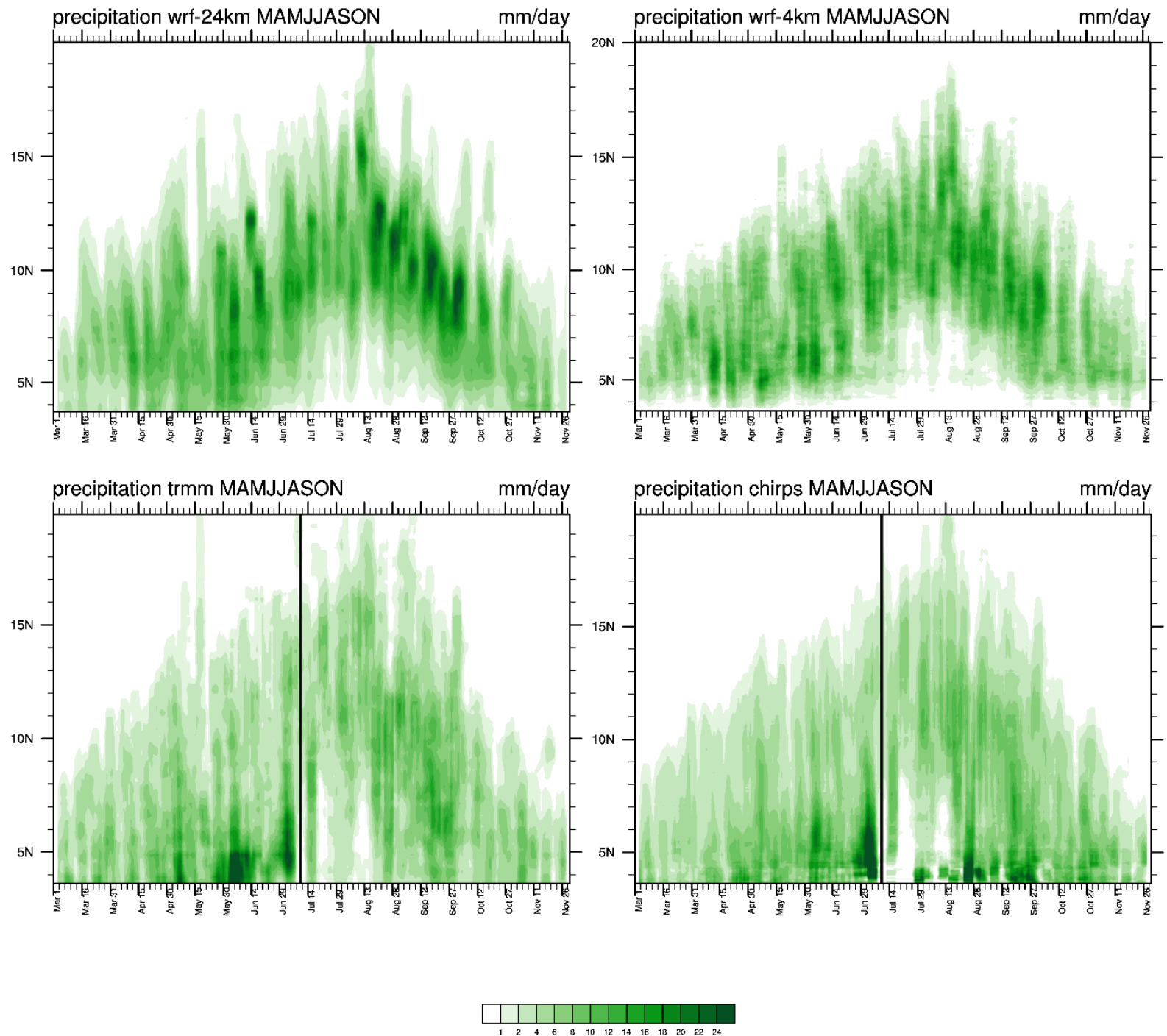

Fig. 2 Seasonal evolution (time vs. latitude) of 5-day mean precipitation averaged between $10^{\circ} \mathrm{W}-10^{\circ} \mathrm{E}$ 

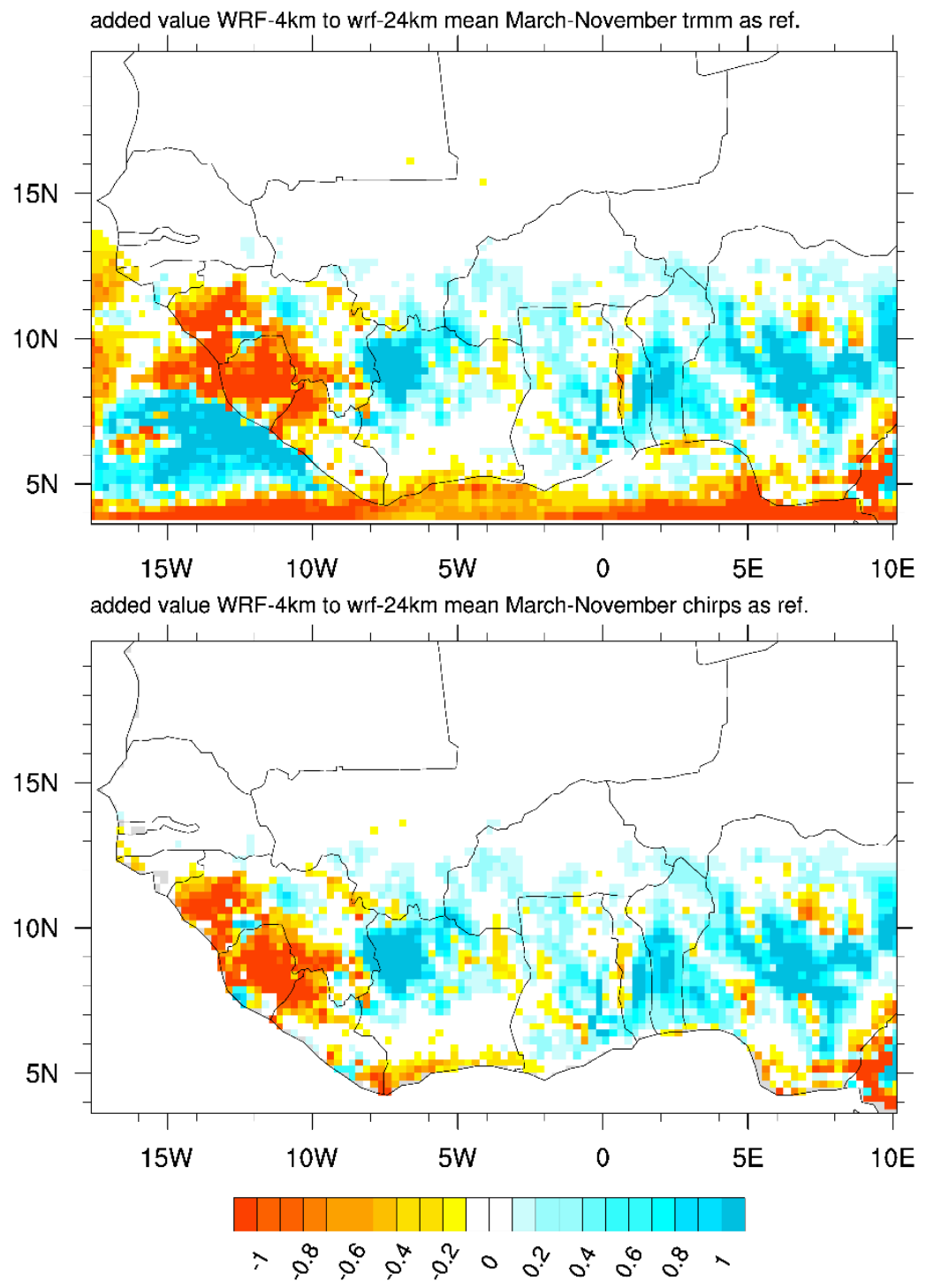

Fig. 3 Added value of high resolution (wrf-4km) simulation to coarse resolution (wrf-24km): on top computed using TRMM as reference dataset and the bottom computed using CHIRPS dataset as the reference. 

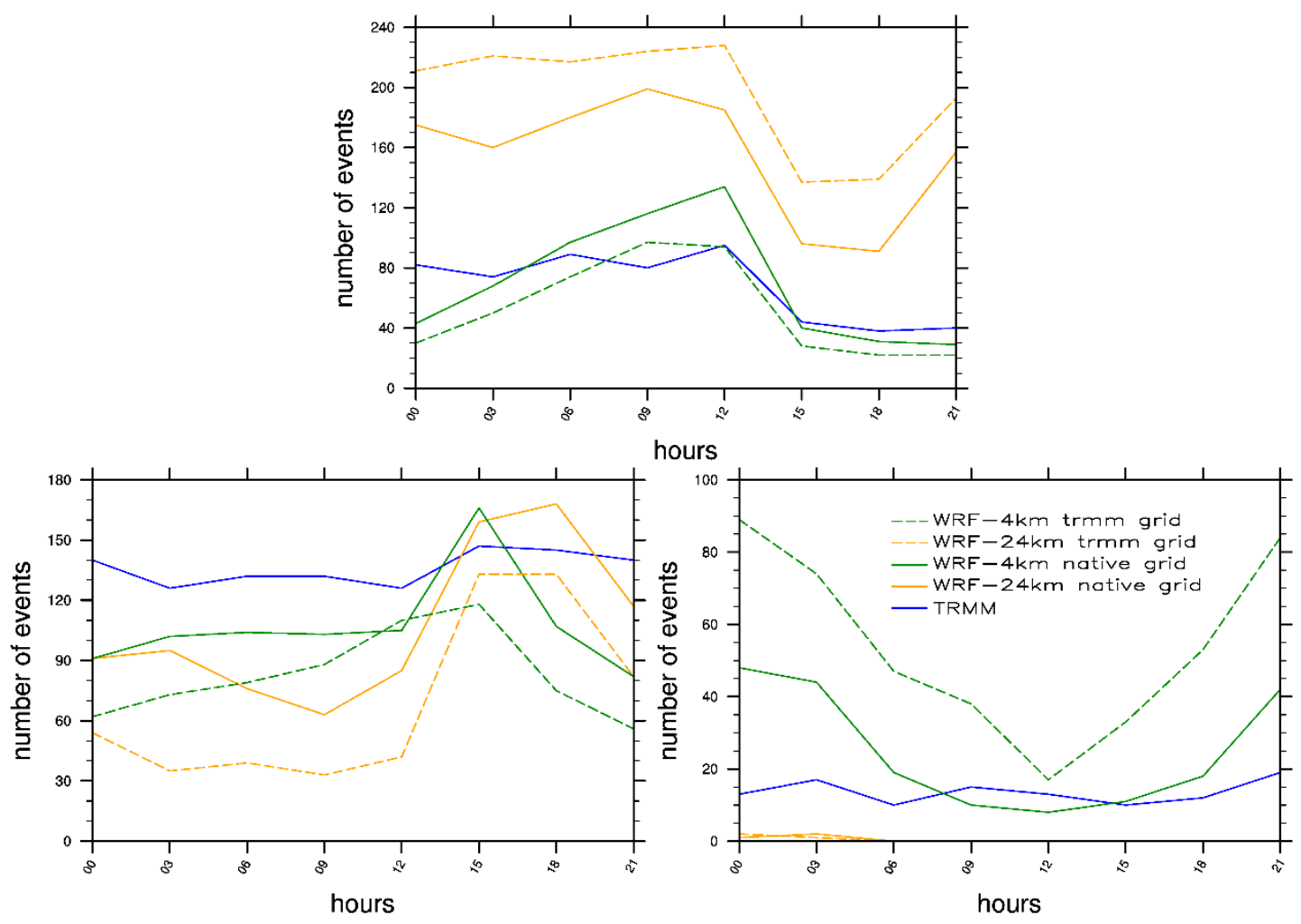

Fig. 4 Diurnal cycle of rainfall occurrence according to the range of intensity computed from TRMM distribution (light, medium, intense); from TRMM (blue), wrf-24km (orange) and wrf$4 \mathrm{~km}$ (green), averaged over Gulf of Guinea $\left(4^{\circ} \mathrm{N}\right.$ to $8^{\circ} \mathrm{N}$ and $10^{\circ} \mathrm{W}$ to $\left.10^{\circ} \mathrm{E}\right)$. The dotted lines account for WRF regrided into TRMM coordinates and the full lines for WRF outputs on native coordinates. Top panel shows light rainfall events; bottom-left and bottom-right present respectively the mediums and intense rainfall events. 

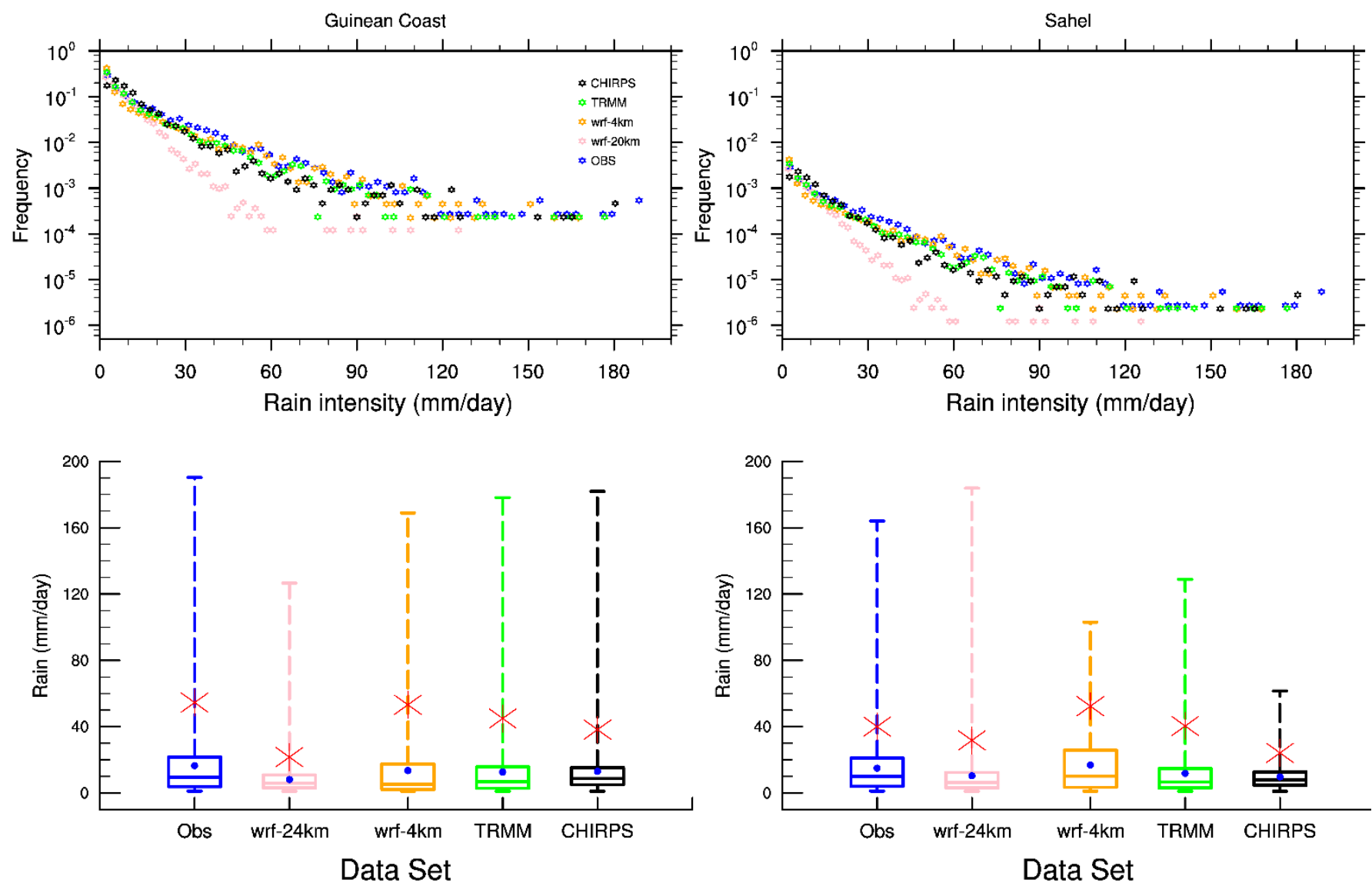

Fig. 5 Empirical probability distribution functions of daily precipitation (top) daily. Boxplots of the daily precipitation (Bottom) respectively from the ground-based observations, wrf-24km, wrf-4km, TRMM and CHIRPS data sets over the Guinean coast (left) and the Sahelian (right) regions. The boxes indicate respectively from the bottom to the top the first, second and third interquartile ranges and the whiskers stretch to minimum and maximum values of each data set. Blue dots and the red stars represent respectively the mean value and the $95^{\text {th }}$ percentile of the precipitation for each data set. 

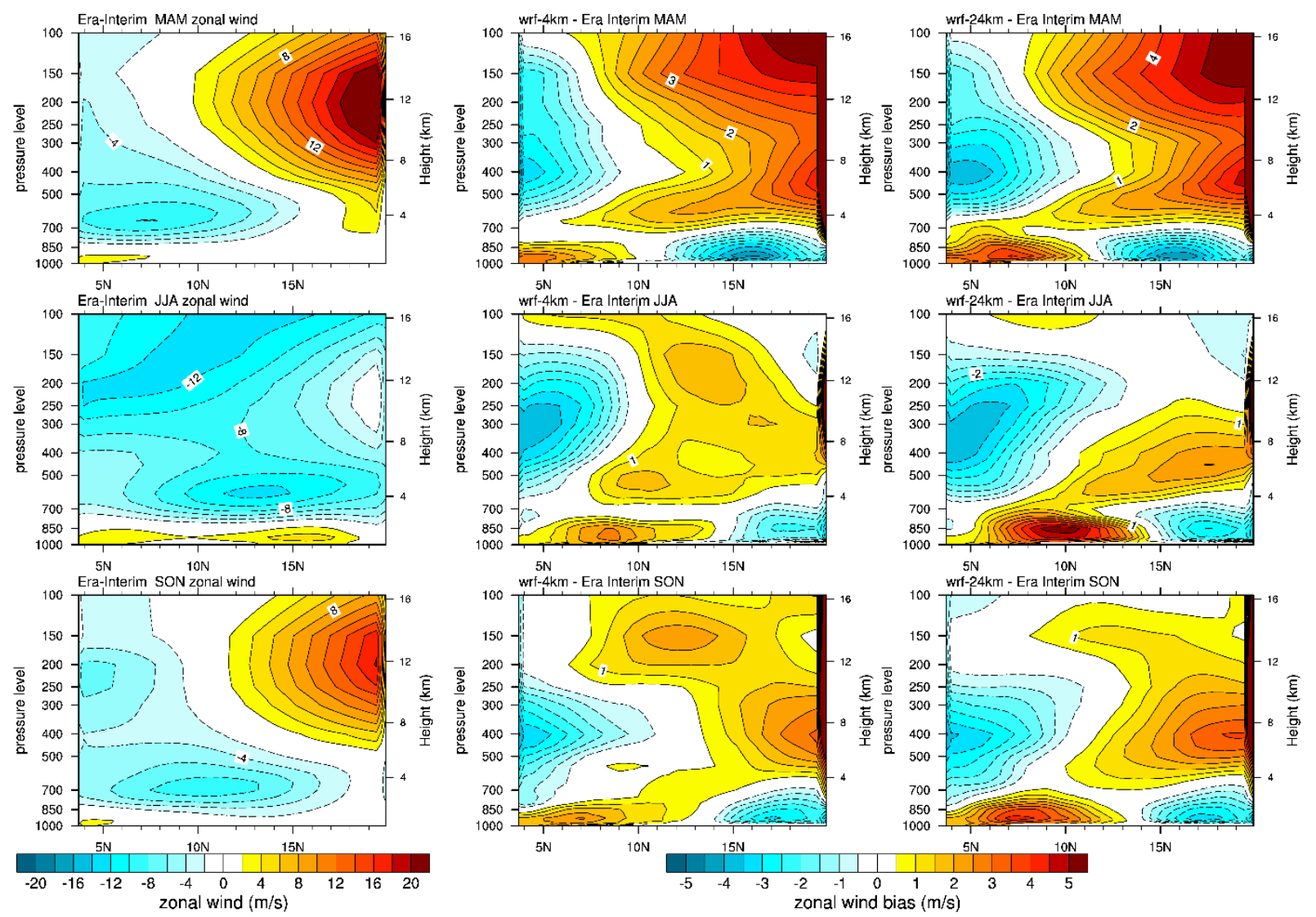

Fig. 6 Seasonal mean cross sections of the zonal wind from March-May, June-August and September-November and averaged from $10^{\circ} \mathrm{W}$ to $10^{\circ} \mathrm{E}$. Column 1 represents ERA-interim; column 2 and column 3 represents respectively the difference between ERA-Interim, wrf-4km and wrf-24km. Dashed contours and blue colours stand for negative values and solid contours and red colours are for positive values. 

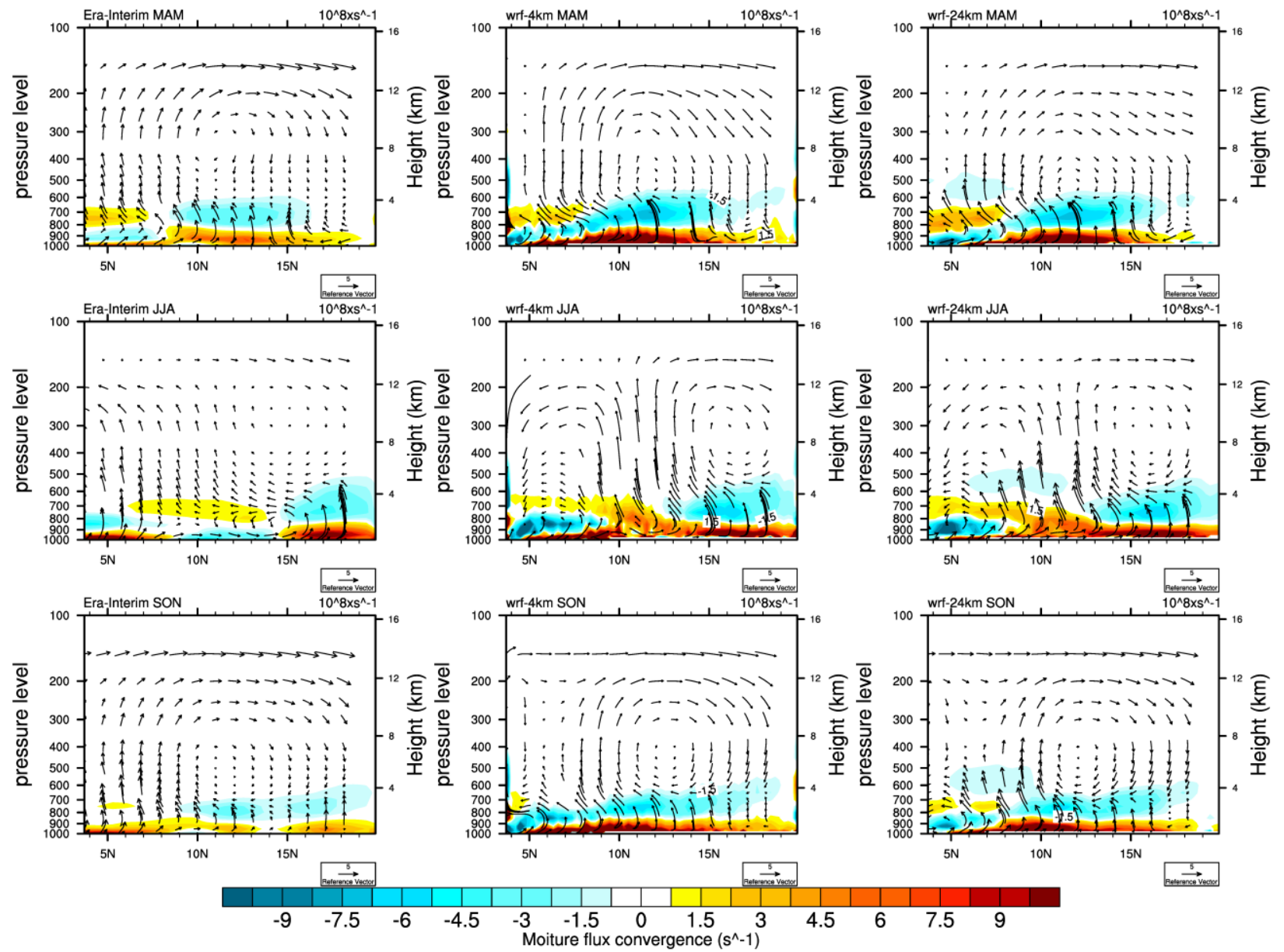

Fig.7 Seasonal mean of vertical profiles of the moisture flux convergence (x $10^{8} \mathrm{~s}^{-1}$, in colour) and the meridional $(\mathrm{m} / \mathrm{s})$ vertical wind vectors $\left(\mathrm{x} 100 \mathrm{~Pa} . \mathrm{s}^{-1}\right)(\mathrm{v}, \mathrm{w})$. All datasets have been regridded into wrf-24km dataset, averaged for the seasons March-May, June-August and September-November and $10^{\circ} \mathrm{W}$ to $10^{\circ} \mathrm{E}$. Column 1 represents ERA-interim; column 2 and column 3 represents respectively wrf-4km and wrf- $24 \mathrm{~km}$. 

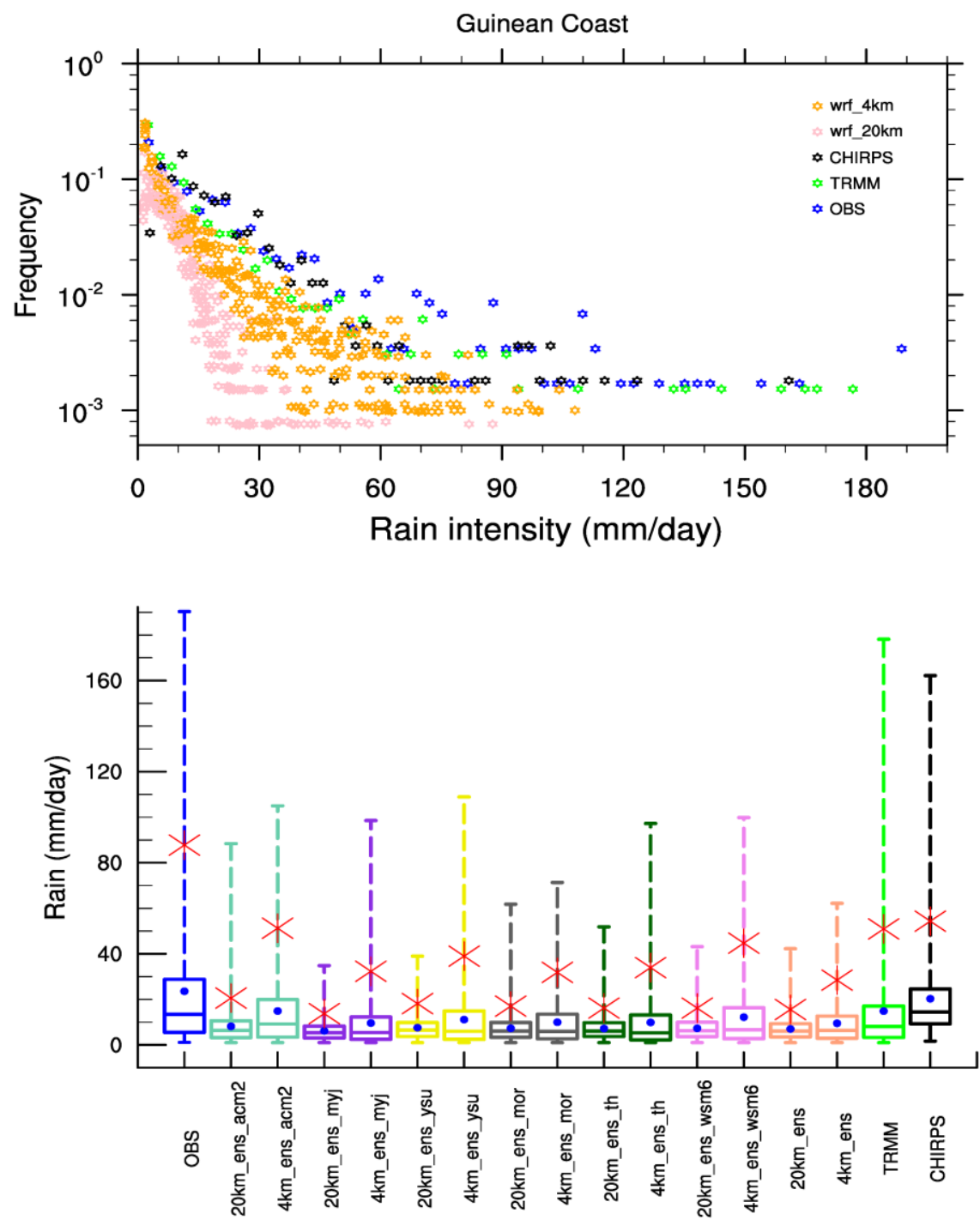

Data Set

Fig. 8 Empirical probability distribution functions of daily precipitation (top) daily. Boxplots of the daily precipitation (Bottom) over the Guinean coast (left) and the Sahelian (right) regions. Boxplots of the daily precipitation over the Guinean coast respectively from the ground-based observation, TRMM, ERA-interim and wrf-24km, wrf-4km from each ensemble group members of the different configurations. The boxes indicate respectively from the bottom to the top the first, second and third interquartile ranges and the whiskers stretch to minimum and maximum values of each data set. Blue dots and the red stars represent respectively the mean value and the 95 percentiles of the precipitation for each data set. 


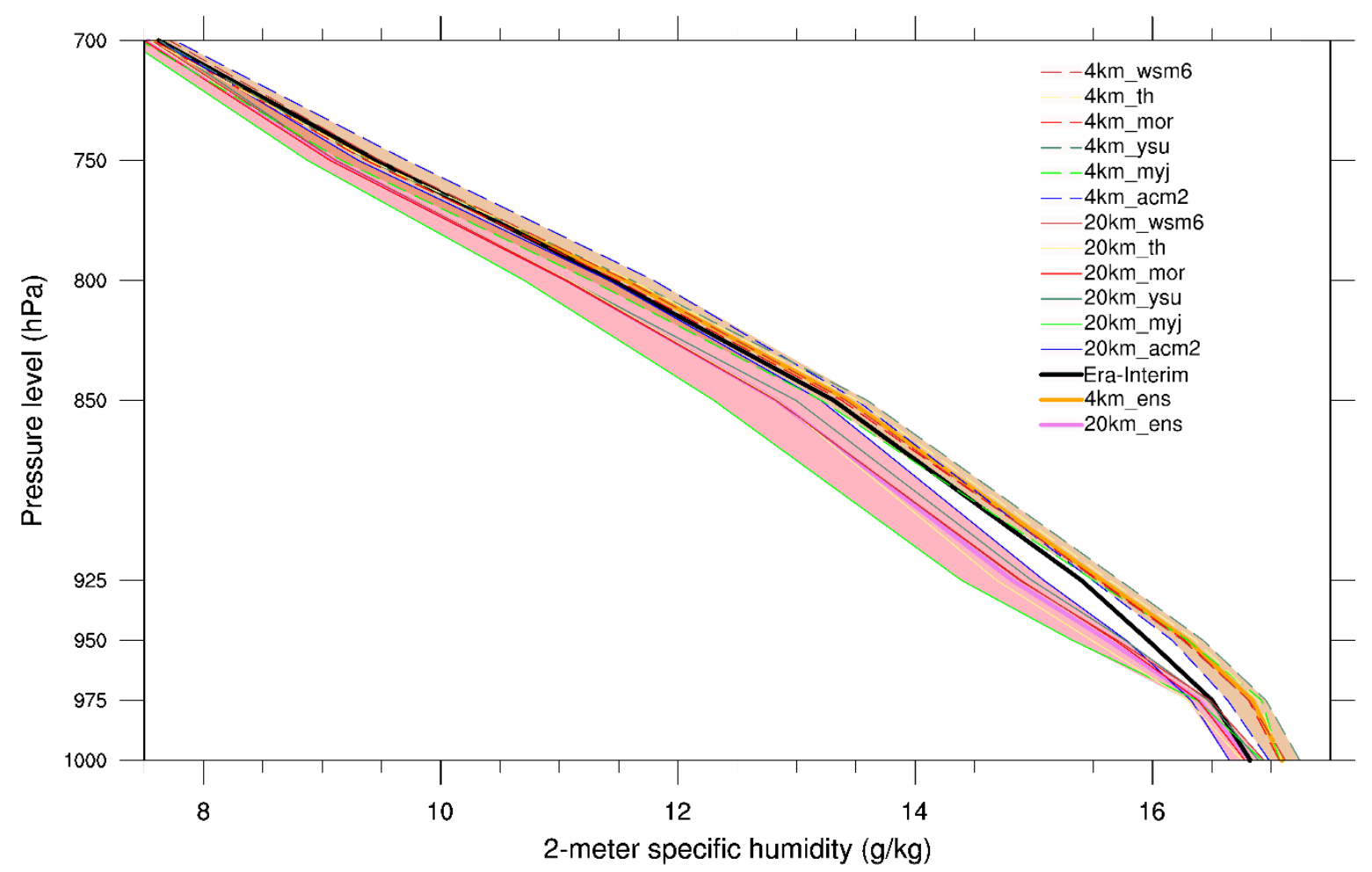

Fig. 9 Vertical profiles of specific humidity from wrf-20km and 4km sub-ensembles group members and Era-interim data set. All the values are averaged from $10 \mathrm{~W}$ to 5E. The pink and orange coloured areas mark the range of value respectively with wrf- $24 \mathrm{~km}$ and wrf4km. 

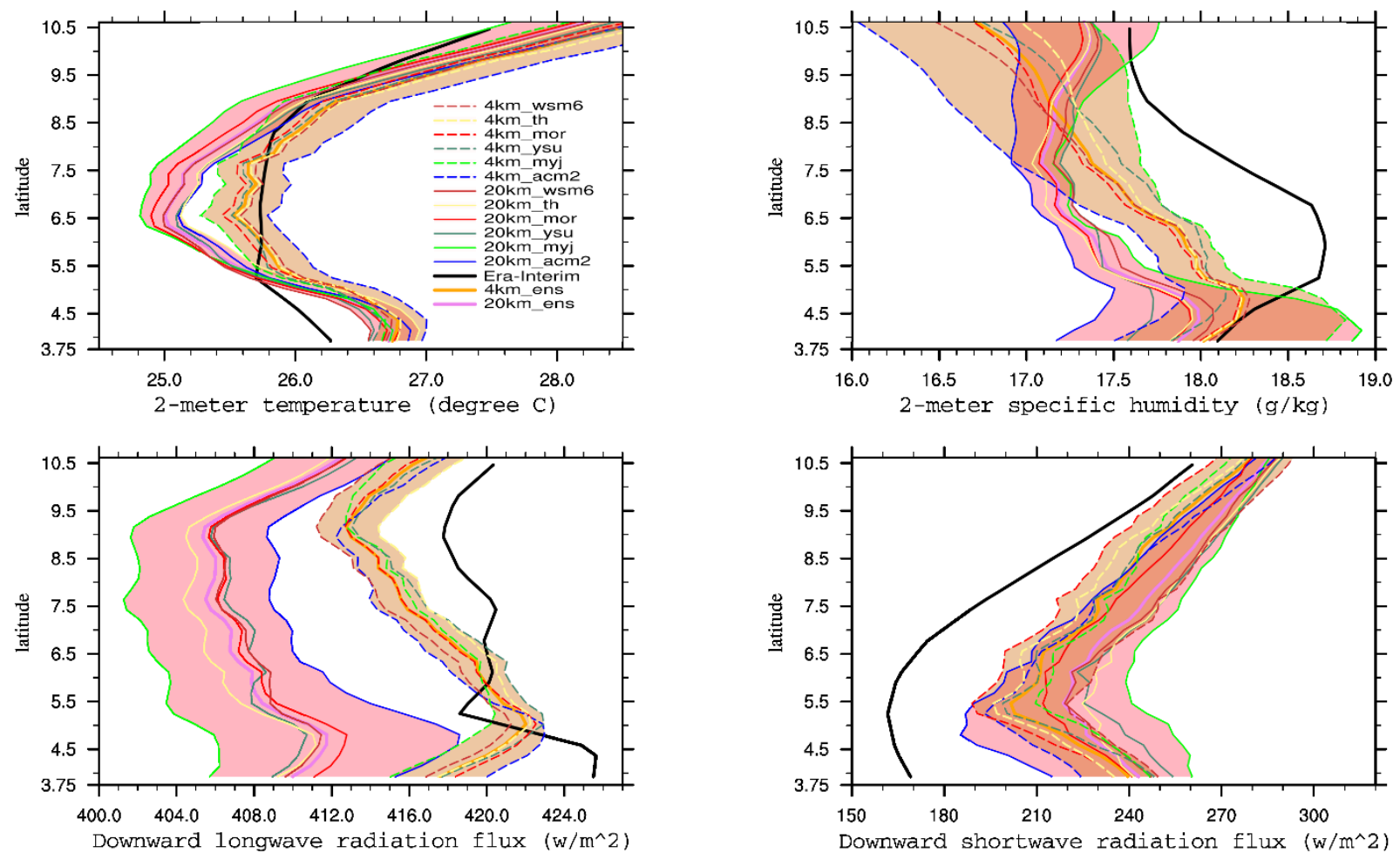

Fig. 10 Meridional evolution of 2-meter temperature, specific humidity, downward shortwave and longwave radiation fluxes from wrf-20km and $4 \mathrm{~km}$ ensemble group members and from Erainterim data set. All the values are averaged from $10 \mathrm{~W}$ to $5 \mathrm{E}$. The pink and orange coloured areas mark the range of value respectively with wrf- $24 \mathrm{~km}$ and wrf $4 \mathrm{~km}$. 

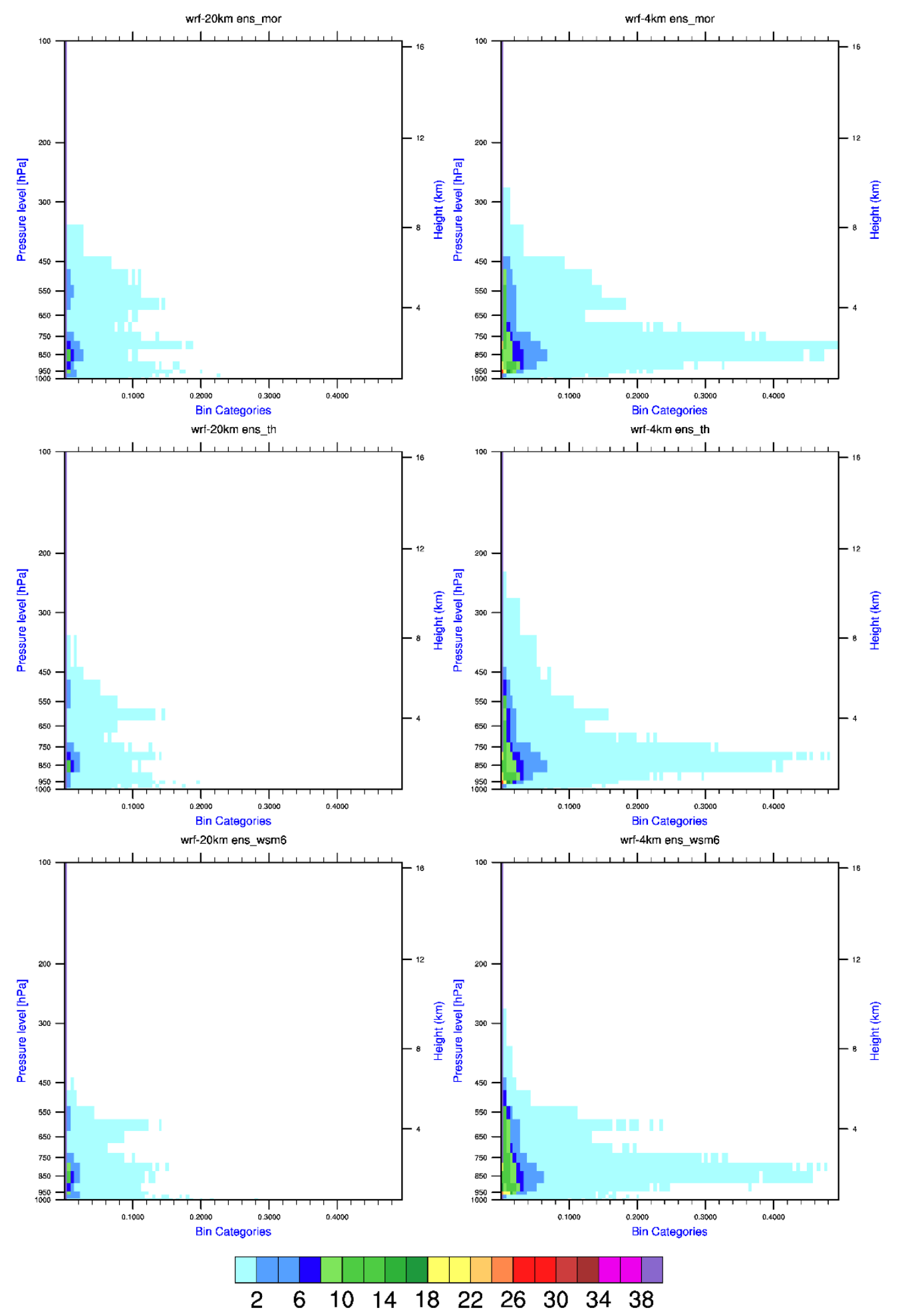

Fig. 11 Liquid Water Content from wrf-20km and 4km ensemble group members and from Era-interim data set. All the values are averaged from $10 \mathrm{~W}$ to $5 \mathrm{E}$. 


\section{References}

763

764

765

766

767

768

769

770

771

772

773

774

775

776

777

778

779

780

781

782

783

784

785

786

787

788

789

790

791

792

793

794

Abiodun BJ, Pal JS, Afiesimama EA, et al (2008) Simulation of West African monsoon using RegCM3 Part II: impacts of deforestation and desertification. Theor Appl Climatol 93:245-261

Adedoyin JA (1989) Global-scale sea-surface temperature anomalies and rainfall characteristics in northern Nigeria. Int J Climatol 9:133-144

Alapaty K, Herwehe JA, Otte TL, et al (2012) Introducing subgrid-scale cloud feedbacks to radiation for regional meteorological and climate modeling: CONVECTION AND RADIATION INTERACTIONS. Geophys Res Lett 39:n/a-n/a. doi: 10.1029/2012GL054031

Ali A, Amani A, Diedhiou A, Lebel T (2005) Rainfall estimation in the Sahel. Part II: Evaluation of rain gauge networks in the CILSS countries and objective intercomparison of rainfall products. J Appl Meteorol 44:1707-1722

Ban N, Schmidli J, Schär C (2014) Evaluation of the convection-resolving regional climate modeling approach in decade-long simulations. J Geophys Res Atmospheres 119:7889-7907

Birch CE, Parker DJ, Marsham JH, et al (2014) A seamless assessment of the role of convection in the water cycle of the West African Monsoon. J Geophys Res Atmospheres 119:2890-2912

Brooks N (2004) Drought in the African Sahel: long term perspectives and future prospects. Tyndall Cent Clim Change Res Norwich Work Pap 61:31

Chang C-P (2011) The Global Monsoon System: Research and Forecast. World Scientific

Chen C-T, Knutson T (2008) On the verification and comparison of extreme rainfall indices from climate models. J Clim 21:1605-1621

Chen F, Dudhia J (2001) Coupling an advanced land surface-hydrology model with the Penn State-NCAR MM5 modeling system. Part I: Model implementation and sensitivity. Mon Weather Rev 129:569-585

Coëtlogon G de, Janicot S, Lazar A (2010a) Intraseasonal variability of the ocean - atmosphere coupling in the Gulf of Guinea during boreal spring and summer. Q J R Meteorol Soc 136:426-441

Coëtlogon G de, Janicot S, Lazar A (2010b) Intraseasonal variability of the ocean - atmosphere coupling in the Gulf of Guinea during boreal spring and summer. Q J R Meteorol Soc 136:426-441

Cook KH (1999) Generation of the African Easterly Jet and Its Role in Determining West African Precipitation. J Clim 12:1165-1184. doi: 10.1175/15200442(1999)012<1165:GOTAEJ>2.0.CO;2

Dee DP, Uppala SM, Simmons AJ, et al (2011) The ERA-Interim reanalysis: configuration and performance of the data assimilation system. Q J R Meteorol Soc 137:553-597. doi: $10.1002 / \mathrm{qj} .828$ 
Di Giuseppe F, Molteni F, Dutra E (2013) Real-time correction of ERA-Interim monthly rainfall. Geophys Res Lett 40:3750-3755

Di Luca A, de Elía R, Laprise R (2012) Potential for added value in precipitation simulated by highresolution nested regional climate models and observations. Clim Dyn 38:1229-1247

Di Luca A, de Elía R, Laprise R (2013) Potential for small scale added value of RCM's downscaled climate change signal. Clim Dyn 40:601-618. doi: 10.1007/s00382-012-1415-z

Dirmeyer PA, Cash BA, Kinter III JL, et al (2012) Simulating the diurnal cycle of rainfall in global climate models: Resolution versus parameterization. Clim Dyn 39:399-418

Doi T, Vecchi GA, Rosati AJ, Delworth TL (2012) Biases in the Atlantic ITCZ in seasonal-interannual variations for a coarse-and a high-resolution coupled climate model. J Clim 25:5494-5511

Dosio A, Panitz H-J, Schubert-Frisius M, Lüthi D (2014) Dynamical downscaling of CMIP5 global circulation models over CORDEX-Africa with COSMO-CLM: evaluation over the present climate and analysis of the added value. Clim Dyn 44:2637-2661. doi: 10.1007/s00382-014$2262-x$

Druyan LM, Feng J, Cook KH, et al (2010) The WAMME regional model intercomparison study. Clim Dyn 35:175-192. doi: 10.1007/s00382-009-0676-7

Dudhia J (1989) Numerical study of convection observed during the winter monsoon experiment using a mesoscale two-dimensional model. J Atmospheric Sci 46:3077-3107

Emori S, Hasegawa A, Suzuki T, Dairaku K (2005) Validation, parameterization dependence, and future projection of daily precipitation simulated with a high-resolution atmospheric GCM. Geophys Res Lett 32:

Evan AT, Flamant C, Lavaysse C, et al (2015) Water vapor-forced greenhouse warming over the Sahara Desert and the recent recovery from the Sahelian drought. J Clim 28:108-123

Fink AH, Schrage JM, Kotthaus S (2010) On the potential causes of the nonstationary correlations between West African precipitation and Atlantic hurricane activity. J Clim 23:5437-5456

Flaounas E, Bastin S, Janicot S (2011) Regional climate modelling of the 2006 West African monsoon: sensitivity to convection and planetary boundary layer parameterisation using WRF. Clim Dyn 36:1083-1105

Flaounas E, Janicot S, Bastin S, Roca R (2012) The West African monsoon onset in 2006: sensitivity to surface albedo, orography, SST and synoptic scale dry-air intrusions using WRF. Clim Dyn 38:685-708

Fontaine B, Louvet S, Roucou P (2008) Definition and predictability of an OLR based West African monsoon onset. Int J Climatol 28:1097-1798

Fontaine B, Philippon N (2000) Seasonal evolution of boundary layer heat content in the West African monsoon from the NCEP/NCAR reanalysis (1968-1998). Int J Climatol 20:1777-1790 
Funk C, Peterson P, Landsfeld M, et al (2015) The climate hazards infrared precipitation with stations-a new environmental record for monitoring extremes. Sci Data 2:150066

Gaetani M, Flamant C, Bastin S, et al (2017) West African monsoon dynamics and precipitation: the competition between global SST warming and CO2 increase in CMIP5 idealized simulations. Clim Dyn 48:1353-1373

Gallée H, Moufouma-Okia W, Bechtold P, et al (2004) A high-resolution simulation of a West African rainy season using a regional climate model. J Geophys Res Atmospheres 109:D05108. doi: 10.1029/2003JD004020

Gbobaniyi E, Sarr A, Sylla MB, et al (2014) Climatology, annual cycle and interannual variability of precipitation and temperature in CORDEX simulations over West Africa. Int J Climatol 34:22412257

Griggs DJ, Noguer M (2002) Climate change 2001: the scientific basis. Contribution of working group I to the third assessment report of the intergovernmental panel on climate change. Weather 57:267269

Grist JP, Nicholson SE (2001) A study of the dynamic factors influencing the rainfall variability in the West African Sahel. J Clim 14:1337-1359

Hagos SM, Cook KH (2007) Dynamics of the West African Monsoon Jump. J Clim 20:5264-5284. doi: 10.1175/2007JCLI1533.1

Harlaß J, Latif M, Park W (2017) Alleviating tropical Atlantic sector biases in the Kiel climate model by enhancing horizontal and vertical atmosphere model resolution: climatology and interannual variability. Clim Dyn 1-31

Herwehe JA, Alapaty K, Spero TL, Nolte CG (2014) Increasing the credibility of regional climate simulations by introducing subgrid-scale cloud-radiation interactions: RCM sims with $\mathrm{Cu}-$ radiation interactions. J Geophys Res Atmospheres 119:5317-5330. doi: 10.1002/2014JD021504

Holloway CE, Neelin JD (2009) Moisture vertical structure, column water vapor, and tropical deep convection. J Atmospheric Sci 66:1665-1683

Holloway CE, Woolnough SJ, Lister GMS (2012) Precipitation distributions for explicit versus parametrized convection in a large-domain high-resolution tropical case study. Q J R Meteorol Soc 138:1692-1708

Holtslag AAM, Boville BA (1993) Local versus nonlocal boundary-layer diffusion in a global climate model. J Clim 6:1825-1842

Hong S-Y, Lim J-OJ (2006) The WRF single-moment 6-class microphysics scheme (WSM6). J Korean Meteor Soc 42:129-151

Hong S-Y, Noh Y, Dudhia J (2006) A new vertical diffusion package with an explicit treatment of entrainment processes. Mon Weather Rev 134:2318-2341 
875

Huffman GJ, Bolvin DT, Nelkin EJ, et al (2007) The TRMM Multisatellite Precipitation Analysis (TMPA): Quasi-Global, Multiyear, Combined-Sensor Precipitation Estimates at Fine Scales. J Hydrometeorol 8:38-55. doi: 10.1175/JHM560.1

Iorio JP, Duffy PB, Govindasamy B, et al (2004) Effects of model resolution and subgrid-scale physics on the simulation of precipitation in the continental United States. Clim Dyn 23:243-258

Janicot S, Mounier F, Gervois S, et al (2010) The dynamics of the West African monsoon. Part V: The detection and role of the dominant modes of convectively coupled equatorial Rossby waves. $\mathbf{J}$ Clim 23:4005-4024

Janjic ZI (1994) The step-mountain eta coordinate model: Further developments of the convection, viscous sublayer, and turbulence closure schemes. Mon Weather Rev 122:927-945

Janjić ZI (2002) Nonsingular implementation of the Mellor-Yamada level 2.5 scheme in the NCEP Meso model. NCEP Off Note 437:61

Kharin VV, Zwiers FW, Zhang X (2005) Intercomparison of near-surface temperature and precipitation extremes in AMIP-2 simulations, reanalyses, and observations. J Clim 18:5201-5223

Klein C, Heinzeller D, Bliefernicht J, Kunstmann H (2015) Variability of West African monsoon patterns generated by a WRF multi-physics ensemble. Clim Dyn 1-23

Konare A, Zakey AS, Solmon F, et al (2008) A regional climate modeling study of the effect of desert dust on the West African monsoon. J Geophys Res 113:. doi: 10.1029/2007JD009322

Laprise R, De Elia R, Caya D, et al (2008) Challenging some tenets of regional climate modelling. Meteorol Atmospheric Phys 100:3-22

Lavaysse C, Diedhiou A, Laurent H, Lebel T (2006) African Easterly Waves and convective activity in wet and dry sequences of the West African Monsoon. Clim Dyn 27:319-332

Lavaysse C, Flamant C, Janicot S, et al (2009) Seasonal evolution of the West African heat low: a climatological perspective. Clim Dyn 33:313-330. doi: 10.1007/s00382-009-0553-4

Lavaysse C, Flamant C, Janicot S (2010a) Regional-scale convection patterns during strong and weak phases of the Saharan heat low. Atmospheric Sci Lett 11:255-264

Lavaysse C, Flamant C, Janicot S, Knippertz P (2010b) Links between African easterly waves, midlatitude circulation and intraseasonal pulsations of the West African heat low. Q J R Meteorol Soc 136:141-158

Lebel T, Diedhiou A, Laurent H (2003) Seasonal cycle and interannual variability of the Sahelian rainfall at hydrological scales. J Geophys Res Atmospheres 1984-2012 108:

Leduc-Leballeur M, De Coëtlogon G, Eymard L (2013) Air-sea interaction in the Gulf of Guinea at intraseasonal time-scales: wind bursts and coastal precipitation in boreal spring. Q J R Meteorol Soc 139:387-400

Leduc-Leballeur M, Eymard L, De Coëtlogon G (2011) Observation of the marine atmospheric boundary layer in the Gulf of Guinea during the 2006 boreal spring. Q J R Meteorol Soc 137:992-1003 
Lind P, Lindstedt D, Kjellström E, Jones C (2016) Spatial and Temporal Characteristics of Summer Precipitation over Central Europe in a Suite of High-Resolution Climate Models. J Clim 29:3501-3518. doi: 10.1175/JCLI-D-15-0463.1

Marsham JH, Dixon NS, Garcia-Carreras L, et al (2013) The role of moist convection in the West African monsoon system: Insights from continental-scale convection-permitting simulations. Geophys Res Lett 40:1843-1849

Meynadier R, Bock O, Gervois S, et al (2010) West African Monsoon water cycle: 2. Assessment of numerical weather prediction water budgets. J Geophys Res Atmospheres 1984-2012 115:

Meynadier R, De Coëtlogon G, Bastin S, et al (2014) Sensitivity testing of WRF parameterizations on air-sea interaction and its impact on water cycle in the Gulf of Guinea. Q J R Meteorol Soc

Mlawer EJ, Taubman SJ, Brown PD, et al (1997) Radiative transfer for inhomogeneous atmospheres: RRTM, a validated correlated-k model for the longwave. J Geophys Res Atmospheres 1984-2012 102:16663-16682

Mohino E, Rodríguez-Fonseca B, Mechoso CR, et al (2011) Impacts of the tropical Pacific/Indian Oceans on the seasonal cycle of the West African monsoon. J Clim 24:3878-3891

Morrison H, Thompson G, Tatarskii V (2009) Impact of cloud microphysics on the development of trailing stratiform precipitation in a simulated squall line: Comparison of one-and two-moment schemes. Mon Weather Rev 137:991-1007

Moufouma-Okia W, Jones R (2014) Resolution dependence in simulating the African hydroclimate with the HadGEM3-RA regional climate model. Clim Dyn 1-24

Moufouma-Okia W, Rowell DP (2010) Impact of soil moisture initialisation and lateral boundary conditions on regional climate model simulations of the West African Monsoon. Clim Dyn $35: 213-229$

Neelin JD, Peters O, Hales K (2009) The Transition to Strong Convection. J Atmospheric Sci 66:23672384. doi: 10.1175/2009JAS2962.1

Nicholson SE (2001) Climatic and environmental change in Africa during the last two centuries. Clim Res 17:123-144

Nicholson SE (2013a) The West African Sahel: A review of recent studies on the rainfall regime and its interannual variability. ISRN Meteorol 2013:

Nicholson SE (2013b) The West African Sahel: A review of recent studies on the rainfall regime and its interannual variability. ISRN Meteorol 2013:

Nicholson SE (2008) The intensity, location and structure of the tropical rainbelt over west Africa as factors in interannual variability. Int J Climatol 28:1775-1785. doi: 10.1002/joc. 1507

Nicholson SE (2009) A revised picture of the structure of the "monsoon" and land ITCZ over West Africa. Clim Dyn 32:1155-1171 
Nicholson SE (2013c) The West African Sahel: A review of recent studies on the rainfall regime and its interannual variability. ISRN Meteorol 2013:

Nicholson SE, Dezfuli AK, Klotter D (2012) A two-century precipitation dataset for the continent of Africa. Bull Am Meteorol Soc 93:1219-1231

Nicholson SE, Grist JP (2003) The seasonal evolution of the atmospheric circulation over West Africa and equatorial Africa. J Clim 16:1013-1030

Oettli P, Sultan B, Baron C, Vrac M (2011) Are regional climate models relevant for crop yield prediction in West Africa? Environ Res Lett 6:14008

Okumura Y, Xie S-P (2004) Interaction of the Atlantic Equatorial Cold Tongue and the African Monsoon*. J Clim 17:3589-3602

Omotosho JB (2008) Pre-rainy season moisture build-up and storm precipitation delivery in the West African Sahel. Int J Climatol 28:937-946. doi: 10.1002/joc.1548

Omotosho JB, Balogun AA, Ogunjobi K, others (2000) Predicting monthly and seasonal rainfall, onset and cessation of the rainy season in West Africa using only surface data. Int J Climatol 20:865880

Omrani H, Drobinski P, Dubos T (2012) Spectral nudging in regional climate modelling: how strongly should we nudge? Q J R Meteorol Soc 138:1808-1813

Panitz H-J, Dosio A, Büchner M, et al (2014) COSMO-CLM (CCLM) climate simulations over CORDEX-Africa domain: analysis of the ERA-Interim driven simulations at 0.44 and 0.22 resolution. Clim Dyn 42:3015-3038

Patricola CM, Li M, Xu Z, et al (2012) An investigation of tropical Atlantic bias in a high-resolution coupled regional climate model. Clim Dyn 39:2443-2463

Pleim JE (2007) A combined local and nonlocal closure model for the atmospheric boundary layer. Part II: Application and evaluation in a mesoscale meteorological model. J Appl Meteorol Climatol 46:1396-1409

Pm. Ruti AD (2009) How do the large-scale models represent the West African intra-seasonal variability and its relationship with remote or local forcing

Pohl B, Crétat J, Camberlin P (2011) Testing WRF capability in simulating the atmospheric water cycle over Equatorial East Africa. Clim Dyn 37:1357-1379

Prein AF, Langhans W, Fosser G, et al (2015) A review on regional convection-permitting climate modeling: Demonstrations, prospects, and challenges. Rev Geophys 53:323-361

Salameh T, Drobinski P, Dubos T (2010) The effect of indiscriminate nudging time on large and small scales in regional climate modelling: application to the Mediterranean basin. Q J R Meteorol Soc 136:170-182

Small RJ, Bacmeister J, Bailey D, et al (2014) A new synoptic scale resolving global climate simulation using the Community Earth System Model. J Adv Model Earth Syst 6:1065-1094 
972

973

974

975

976

978

979

980

981

982

983

984

985

986

987

988

989

990

991

992

993

994

995

996

997

998

999

1000

1001

1002

1003

Stauffer DR, Seaman NL (1990) Use of four-dimensional data assimilation in a limited-area mesoscale model. Part I: Experiments with synoptic-scale data. Mon Weather Rev 118:1250-1277

Steiner AL, Pal JS, Rauscher SA, et al (2009) Land surface coupling in regional climate simulations of the West African monsoon. Clim Dyn 33:869-892

Stephens GL, L'Ecuyer T, Forbes R, et al (2010) Dreary state of precipitation in global models. J Geophys Res Atmospheres 115:

Sultan B, Janicot S (2000) Abrupt shift of the ITCZ over West Africa and intra-seasonal variability. Geophys Res Lett 27:3353-3356

Sultan B, Janicot S (2003) The West African monsoon dynamics. Part II: The "preonset" and "onset" of the summer monsoon. J Clim 16:3407-3427

Sultan B, Janicot S, Diedhiou A (2003) The West African monsoon dynamics. Part I: Documentation of intraseasonal variability. J Clim 16:3389-3406

Sylla MB, Coppola E, Mariotti L, et al (2010a) Multiyear simulation of the African climate using a regional climate model (RegCM3) with the high resolution ERA-interim reanalysis. Clim Dyn $35: 231-247$

Sylla MB, Dell'Aquila A, Ruti PM, Giorgi F (2010b) Simulation of the intraseasonal and the interannual variability of rainfall over West Africa with RegCM3 during the monsoon period. Int J Climatol 30:1865-1883

Tao W-K, Moncrieff MW (2009) Multiscale cloud system modeling. Rev Geophys 47:

Thompson G, Field PR, Rasmussen RM, Hall WD (2008) Explicit forecasts of winter precipitation using an improved bulk microphysics scheme. Part II: Implementation of a new snow parameterization. Mon Weather Rev 136:5095-5115

Trenberth KE, Stepaniak DP, Caron JM (2000) The global monsoon as seen through the divergent atmospheric circulation. J Clim 13:3969-3993

Vizy EK (2002) Development and application of a mesoscale climate model for the tropics: Influence of sea surface temperature anomalies on the West African monsoon. J Geophys Res 107:. doi: 10.1029/2001JD000686

Xie B, Fung JC, Chan A, Lau A (2012) Evaluation of nonlocal and local planetary boundary layer schemes in the WRF model. J Geophys Res Atmospheres 1984-2012 117:

Zhang C, Woodworth P, Gu G (2006) The seasonal cycle in the lower troposphere over West Africa from sounding observations. Q J R Meteorol Soc 132:2559-2582 
Click here to download Figure Fig.1.png $\underline{\underline{ }}$
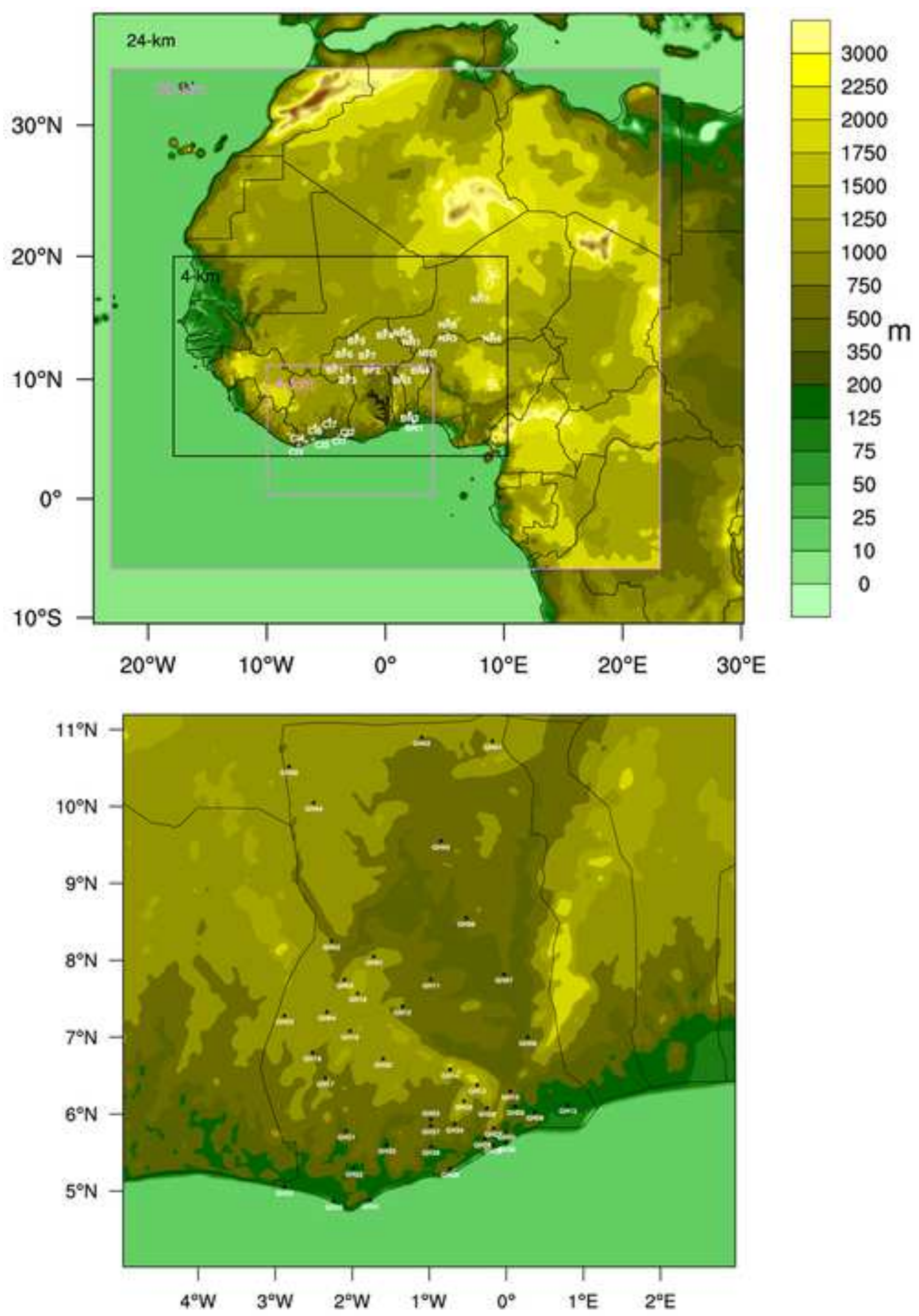


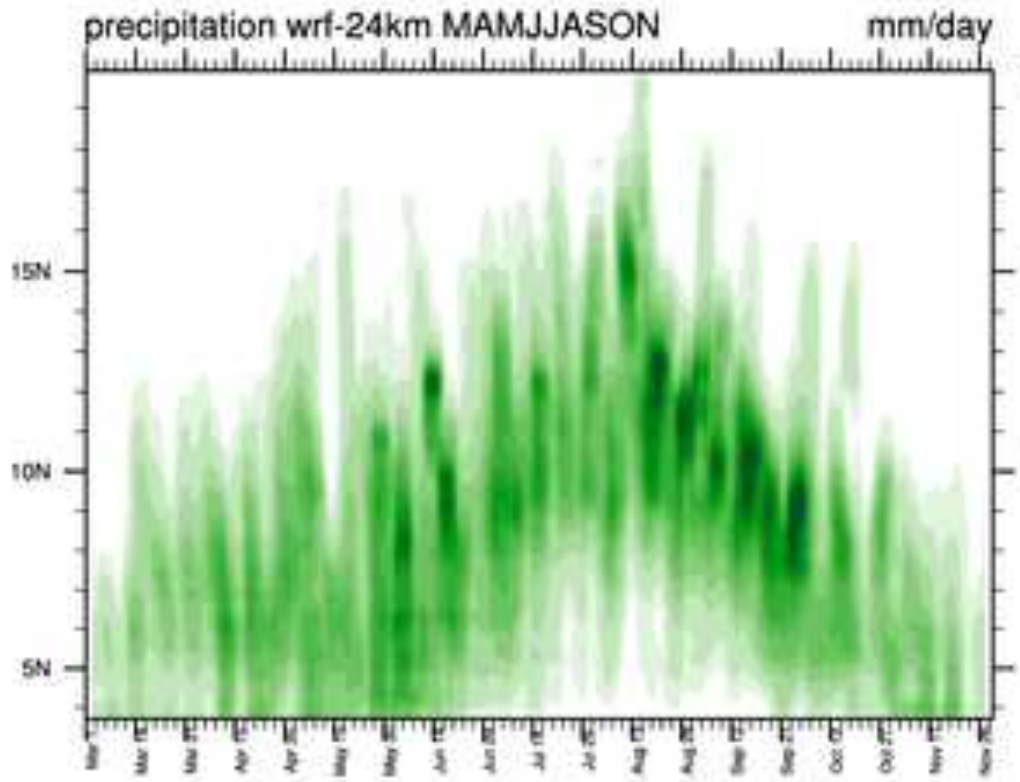

precipitation wrf-4km MAMJJASON

$\mathrm{mm} / \mathrm{day}$
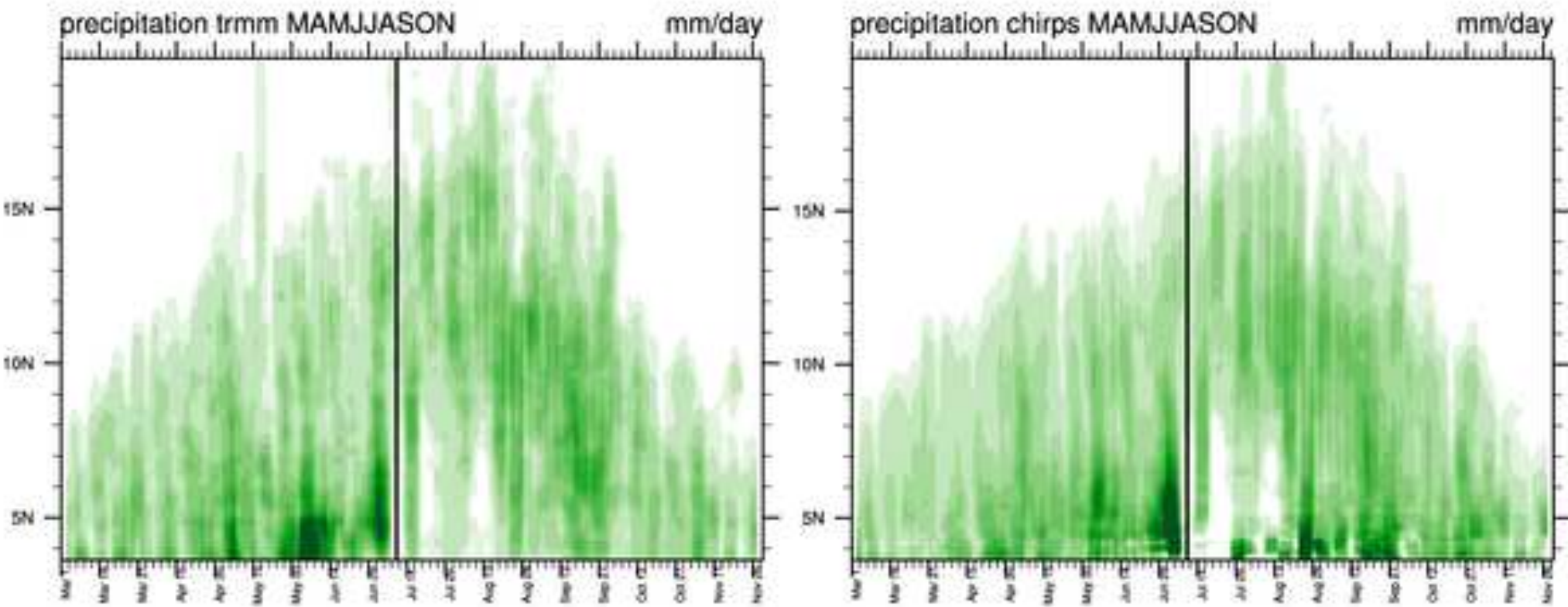

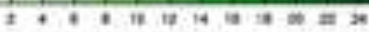




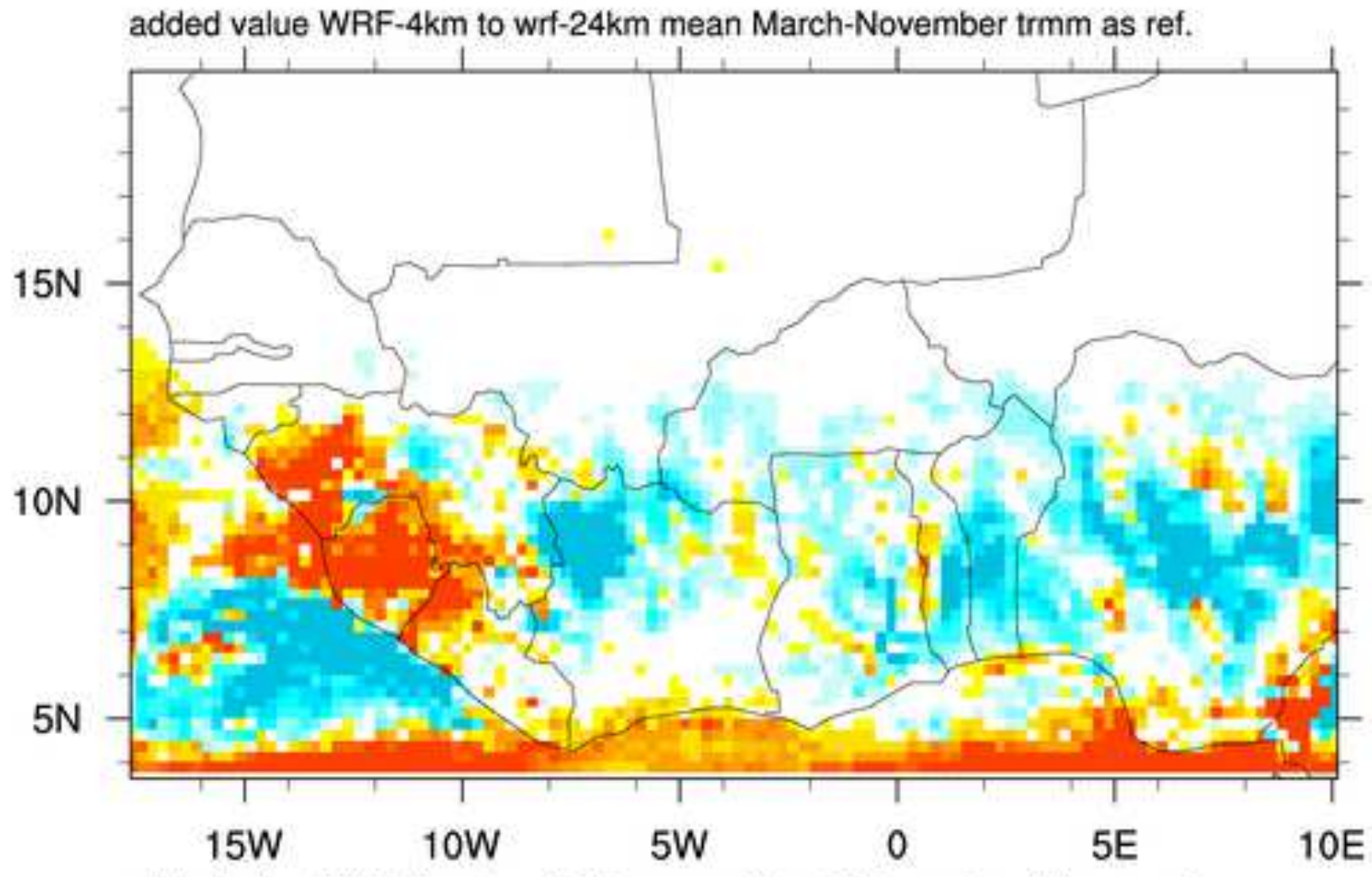

added value WRF-4km to wrf-24km mean March-November chirps as ref.

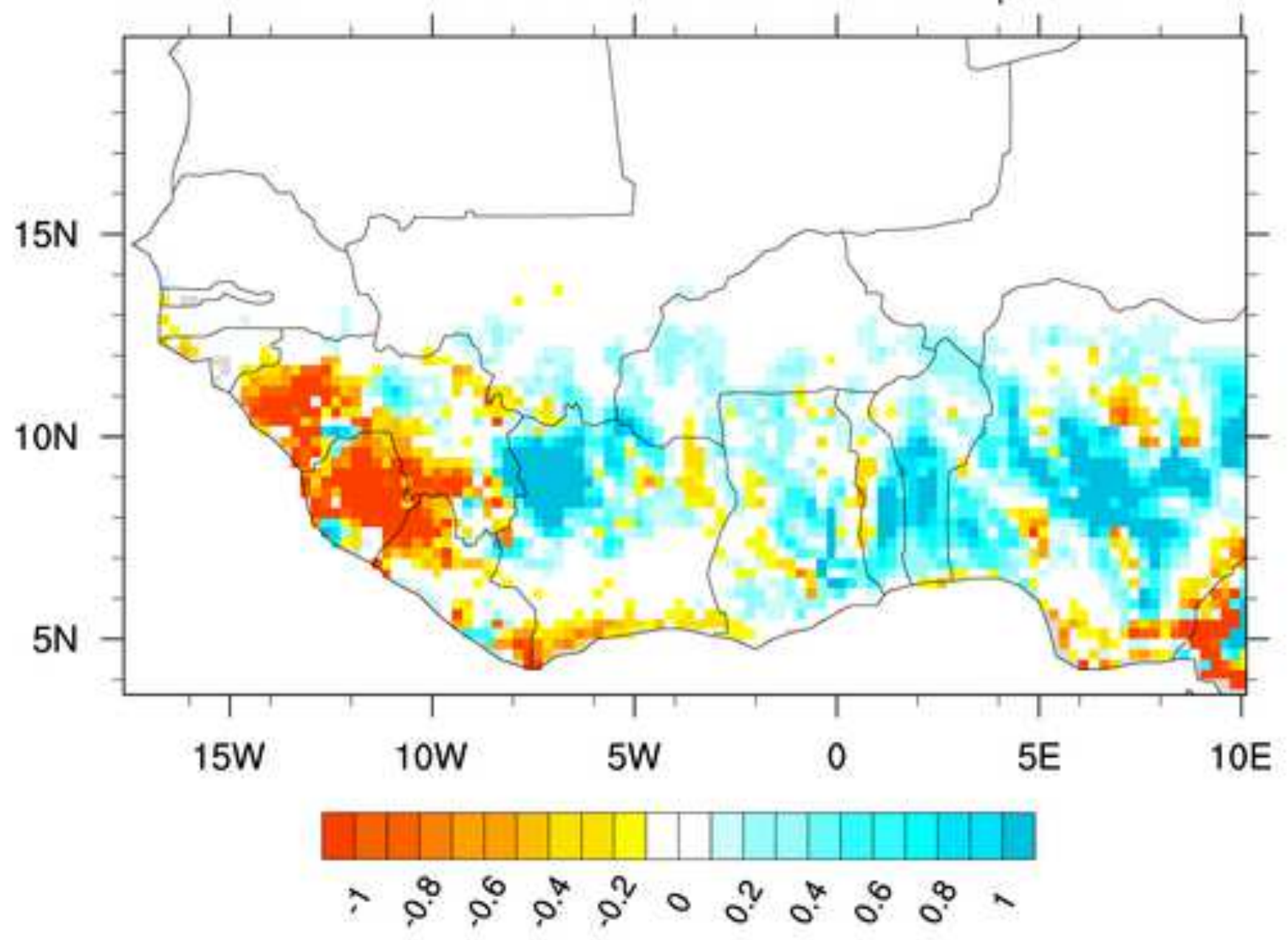



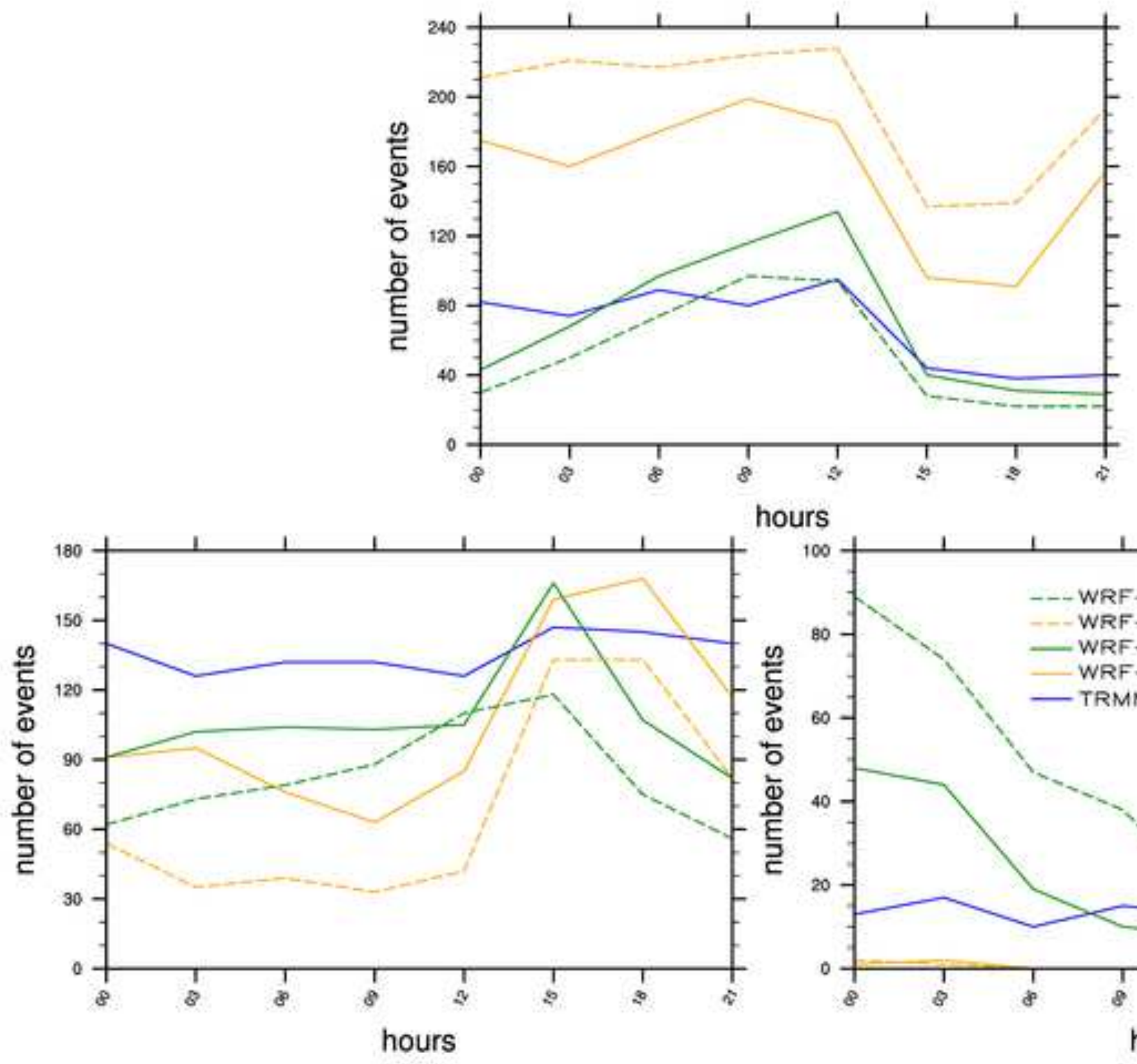

hours

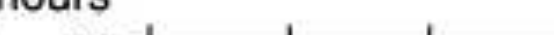

100

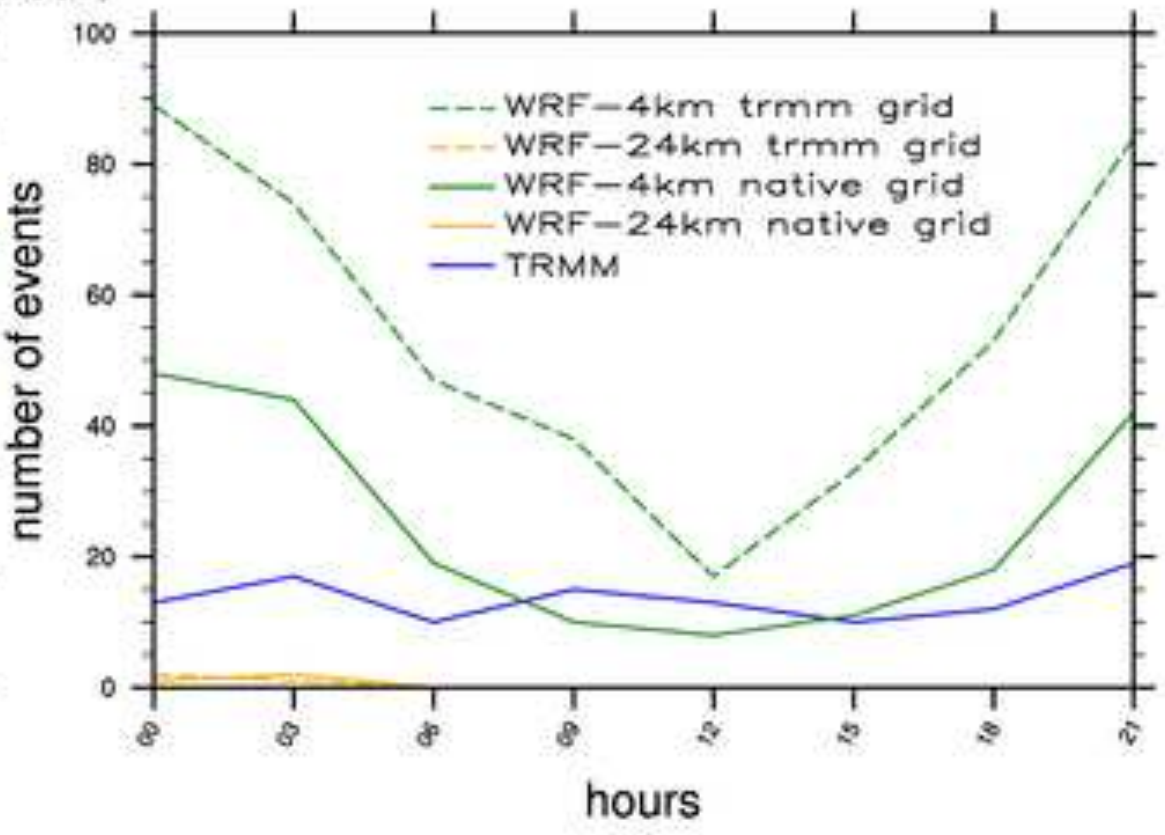



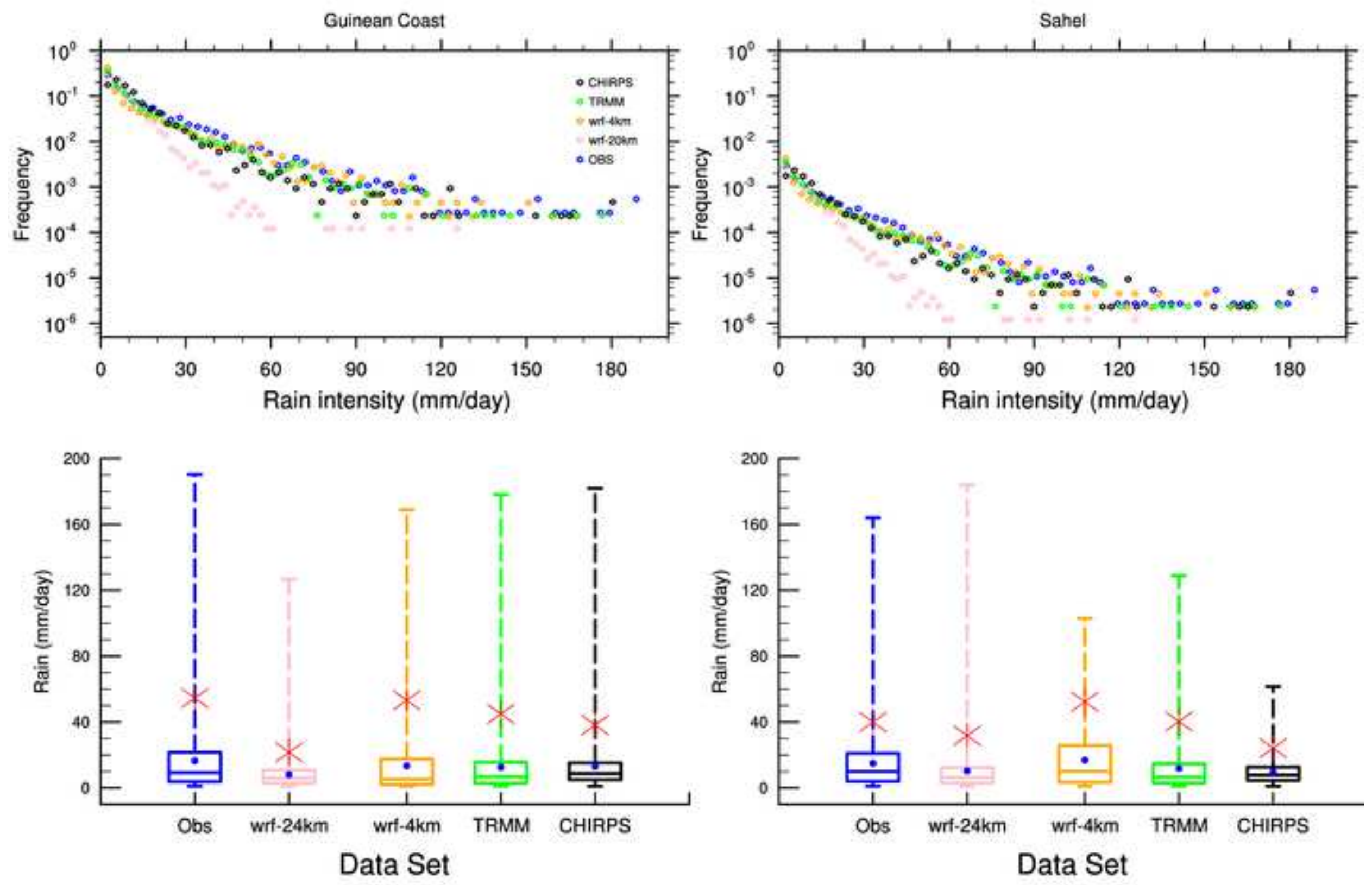

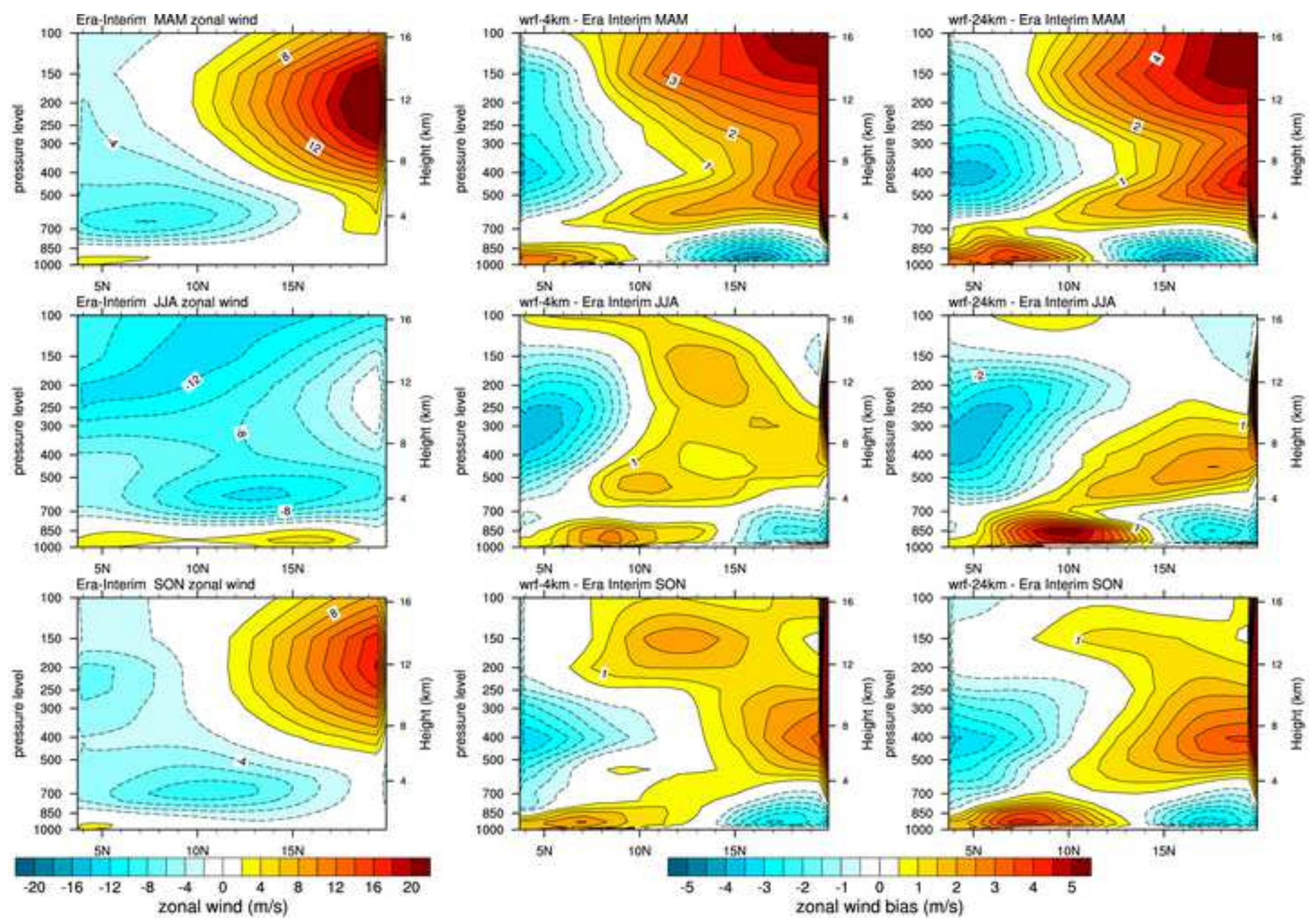

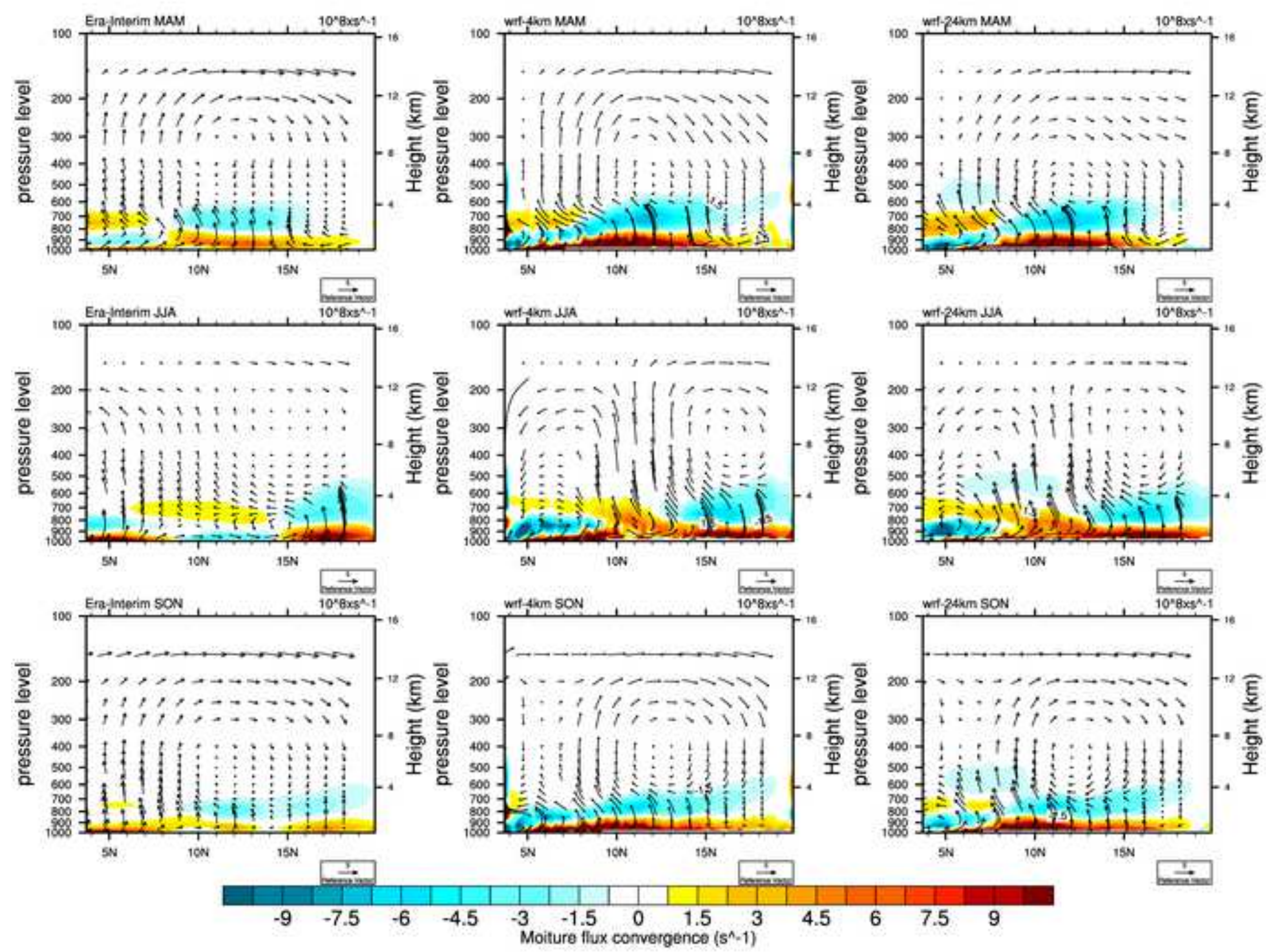


\section{Guinean Coast}
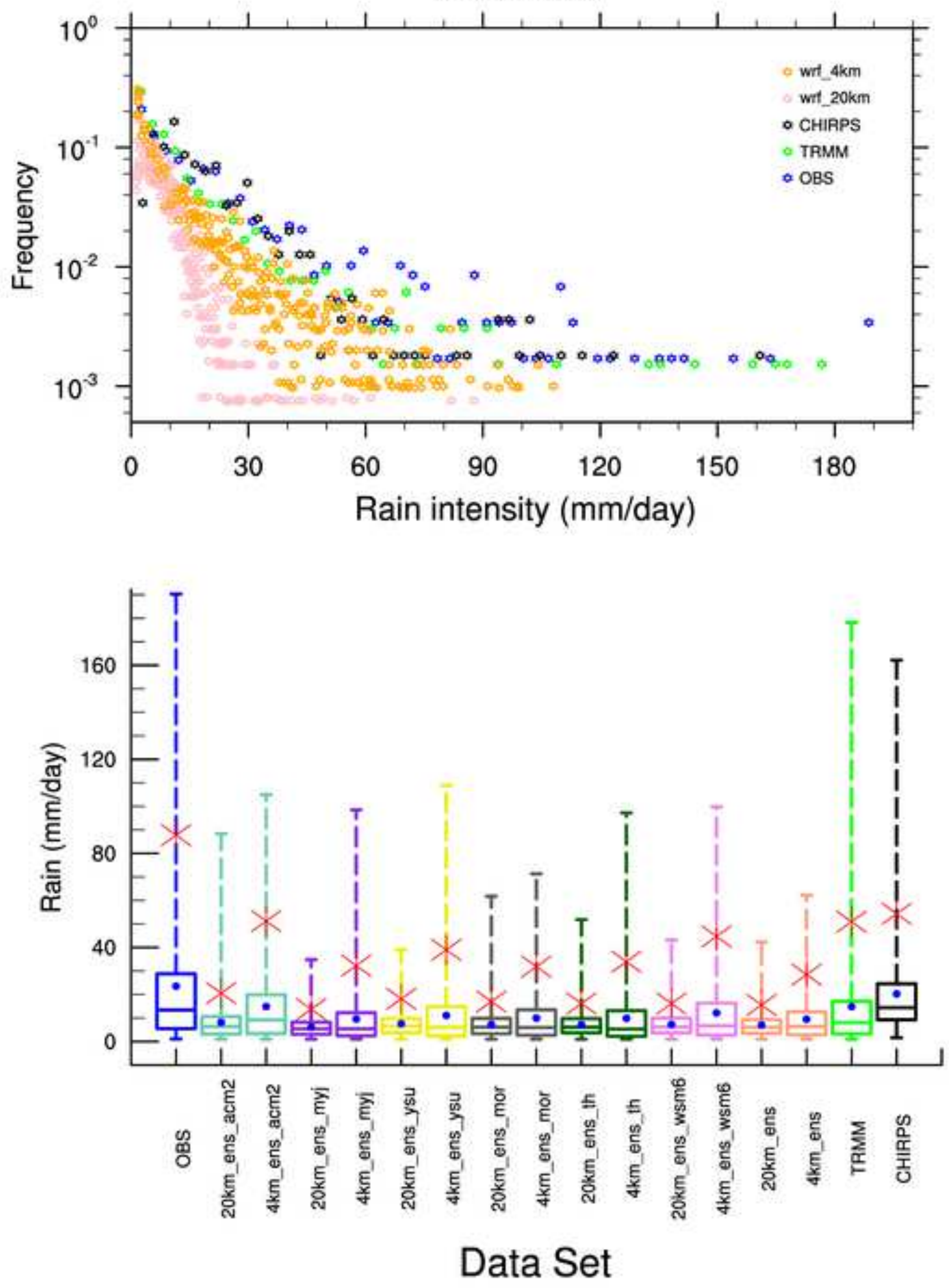


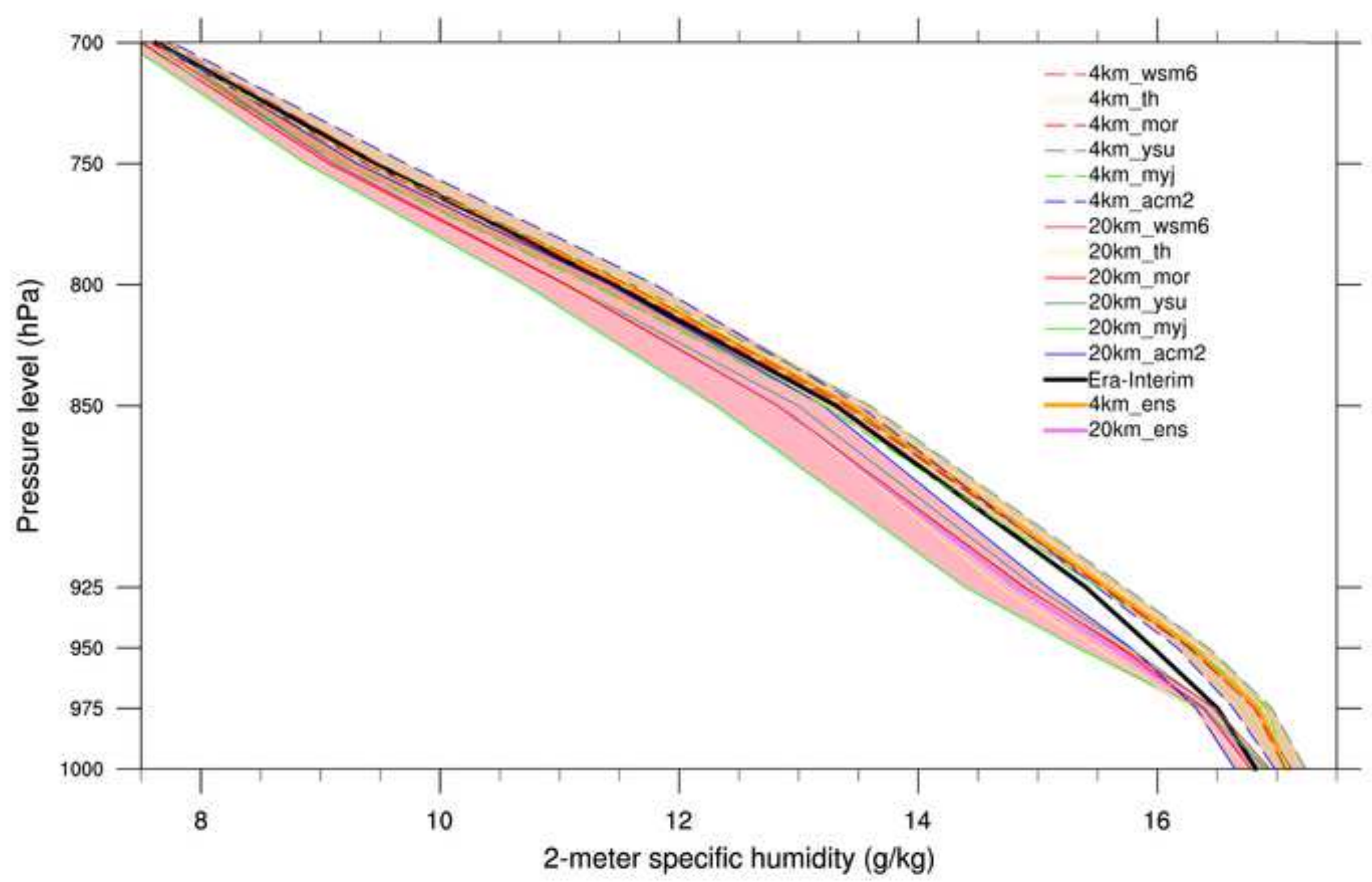



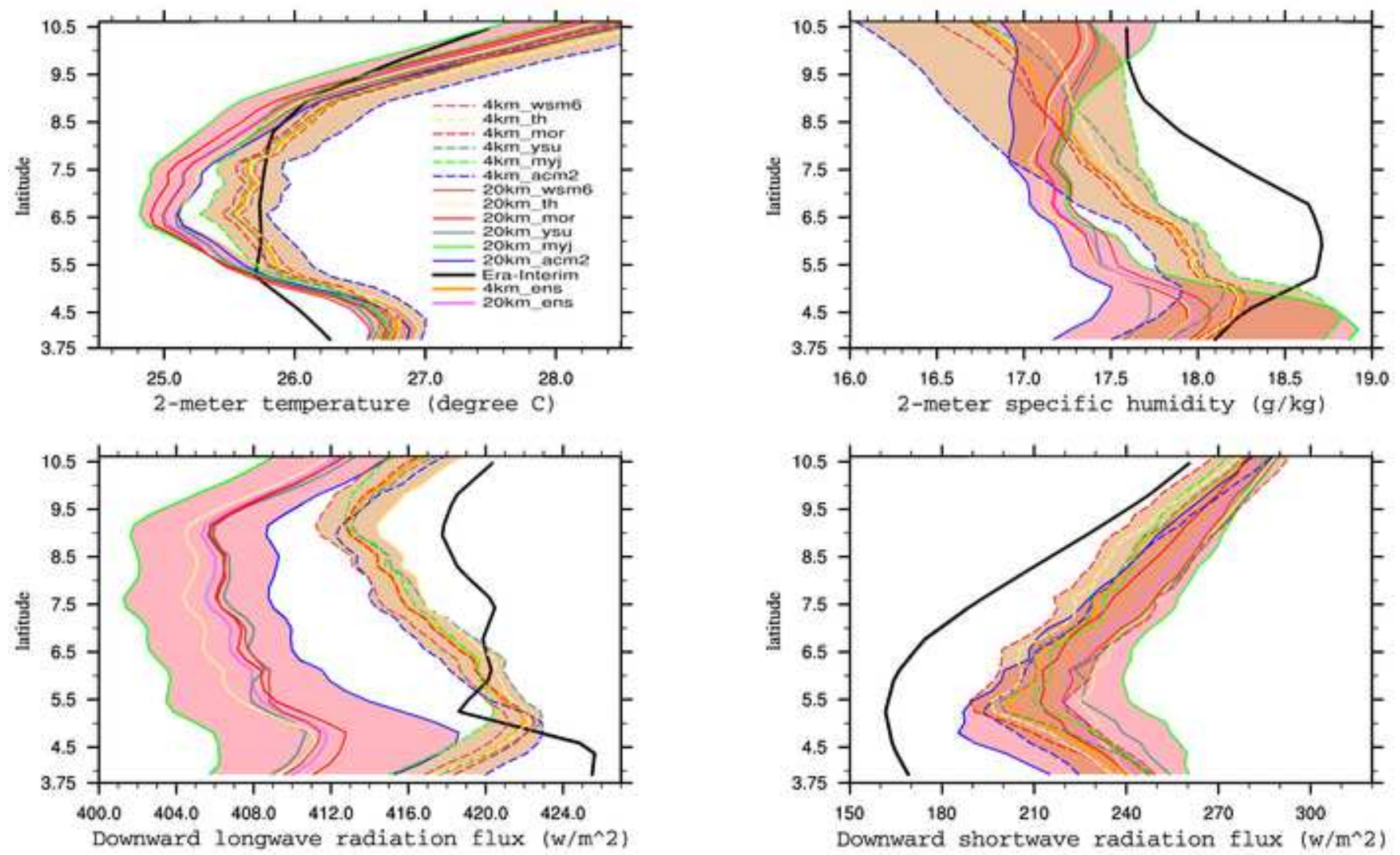
Click here to download Figure Fig.11.png $\underline{\underline{ }}$
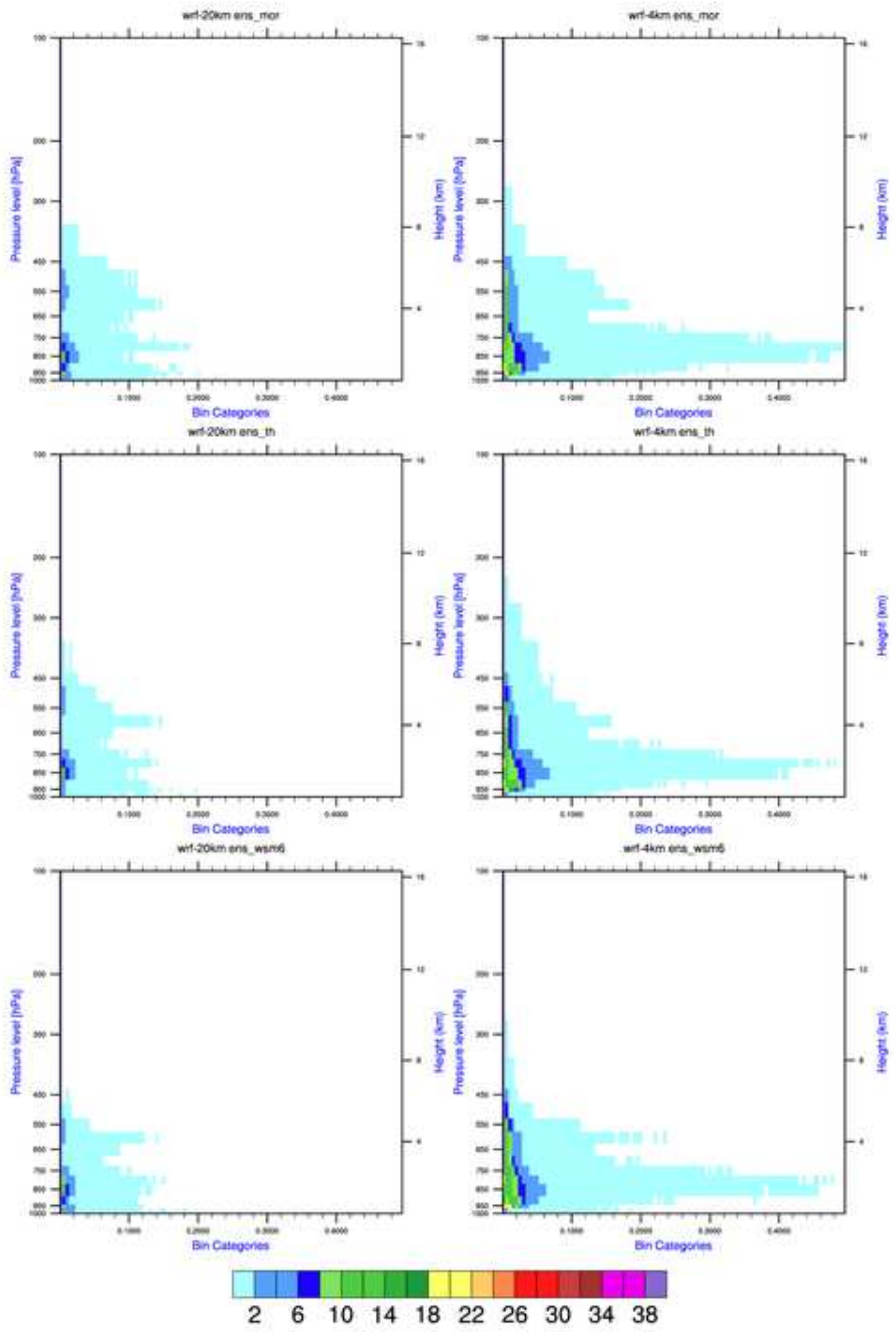